\title{
Nanoprecipitation in a Beta-Titanium Alloy
}

\author{
James Coakley ${ }^{\mathrm{a}, *}$, Vassili A Vorontsov ${ }^{\mathrm{a}}$, Kenneth C Littrell ${ }^{\mathrm{b}}$, Richard K Heenan ${ }^{\mathrm{c}}$, Masato Ohnuma ${ }^{\mathrm{d}}$, Nicholas G \\ Jones $^{\mathrm{e}}$, David Dye $\mathrm{a}^{\mathrm{a}}$ \\ ${ }^{a}$ Department of Materials, Imperial College, South Kensington, London SW7 2AZ, England \\ ${ }^{b}$ Oak Ridge National Laboratory, Chemical and Engineering Materials Division, Oak Ridge, TN 37831, USA \\ ${ }^{c}$ Rutherford Appleton Laboratory, Didcot, Oxon OX11 OQX, England \\ ${ }^{d}$ Laboratory of Quantum Beam System Engineering, Hokkaido University, Sapporo 060-0808, Japan \\ ${ }^{e}$ Department of Materials Science and Metallurgy, University of Cambridge, Cambridge CB2 3QZ, England
}

\begin{abstract}
This paper represents the first application of small angle neutron scattering (SANS) to the study of precipitate nucleation and growth in $\beta$-Ti alloys in an attempt to observe both the precipitation process in-situ and to quantify the evolving microstructure that affects mechanical behaviour. TEM suggests that athermal $\omega$ can be induced by cold-rolling Gum metal, a $\beta$-Ti alloy. During thermal exposure at $400^{\circ} \mathrm{C}$, isothermal $\omega$ particles precipitate at a greater rate in cold-rolled material than in the recovered, hot deformed state. SANS modelling is consistent with disc shaped nanoparticles, with length and radius under $6 \mathrm{~nm}$ after thermal exposures up to $16 \mathrm{~h}$. Modelling suggests that the nanoprecipitate volume fraction and extent of $\mathrm{Nb}$ partitioning to the $\beta$ matrix is greater in the cold-rolled material than the extruded. The results show that nucleation and growth of the nanoprecipitates impart strengthening to the alloy.
\end{abstract}

Key words: Metals and Alloys, Precipitation, Transmission Electron Microscopy, TEM, Neutron Scattering, Titanium Alloys

\section{Introduction}

The use of $\beta$-titanium alloys in industry is steadily in- ${ }^{27}$ creasing due to their attractive properties. The low elastic modulus is of significance for orthopaedic applications, and ${ }^{29}$ the high yield strength is a requirement for aero applications such as landing gear. Ultimate tensile strengths far ${ }^{31}$ in excess of $1 \mathrm{GPa}$ have been reported $[1,2]$. However, the mechanisms producing this level of strength are still not ${ }_{34}^{33}$ fully understood. Raghunathan et al. [3] attribute the ${ }_{35}^{34}$ high strength of Ti-10V-2Fe-3Al $\beta$-Ti alloy to fine scale $\alpha^{35}$ precipitates, which create a high number of $\beta / \alpha$ interfaces ${ }^{36}$ that hinder dislocation motion through the matrix. Nag et ${ }^{37}$ al. attribute high strength in a TNZT (Ti-Nb-Zr-Ta) $\beta-\mathrm{Ti}^{38}$ alloy to metastable B2 ordering in the matrix and found ${ }^{39}$ that precipitation of fine scale $\alpha$ particles destroyed this ${ }^{40}$ ordering, thereby softening the material [4].

The attribution of strengthening mechanisms in $\beta-\mathrm{Ti}^{42}$ alloys is further complicated by the metastable athermal ${ }^{43}$ $\omega\left(\omega_{\text {ath }}\right)$ and isothermal $\omega\left(\omega_{\text {iso }}\right)$ phases that can nucleate ${ }_{45}$ on quenching and appropriate ageing respectively. $\omega_{\text {ath }}$ forms from the $b c c \beta$ lattice by displacement of two $\{111\}_{\beta}$ planes $[5,6]$. It appears that the $\omega_{\text {iso }}$ phase is a continuation of the $\omega_{\text {ath }}$ transformation, such that after the $\omega_{\text {ath }}$ structure is formed, $\beta$ stabilising elements are continuously rejected from the $\omega$ interface during isothermal 2269

*Corresponding Author. Tel: +1 312774 8634; fax: +1 847467

Email address: j.coakley06@imperial.ac.uk (James Coakley) ageing [7]. The precipitation mechanism from quenching to a stable precipitate on appropriate heat-treatment in a binary $\beta$-Ti alloy (Ti-18Mo wt.\%) is believed to be $\beta \rightarrow \beta+\beta^{\prime} \rightarrow \beta^{\prime}+\omega \rightarrow \beta^{\prime}+\omega+\alpha \rightarrow \beta^{\prime}+\alpha$ [8], where $\beta$ and $\beta^{\prime}$ are solute lean and solute rich bcc phases respectively. It is unknown if this precipitation path holds true for more highly alloyed $\beta$-Ti alloys.

Nag concluded that the dissolution of $\omega$ on ageing causes a reduction in hardness in Ti-15Mo [4], while Jones et al. concluded that the $\omega$ does not impart strengthening, and attributes an increase in strength to precipitation of nanoscale $\alpha$ laths in Ti-5Al-5Mo-5V-3Cr (Ti-5553) [9]. This brief literature review shows that there is much confusion over the strengthening phases in high strength $\beta$-Ti alloys. In this work, pinhole small angle neutron scattering (SANS) is used in conjunction with X-ray diffraction (XRD) and extensive complementary transmission electron microscopy (TEM) to study the precipitation process in-situ of Gum metal, a $\beta$-Ti alloy. The aim has been to implement an additional scientific technique to aid the un-

The term 'Gum metal' refers to an alloy composition range defined by Saito et al. that exhibit "super properties": ultralow elastic modulus, ultrahigh strength, superelasticity and superplasticity, at room temperature, as well as invar and elinvar properties $[1,10]$. The fundamental composition of Gum metals are Ti-24(Nb+Ta+V)(Zr,Hf)-O (at.\%), and must satisfy specific values of average electron valence number, bond order and d-electron orbital energy, to ensure $\beta$ phase stability. Thus a range of alloys may be referred to as Gum metal. 
Table 1: Comparison of similar biomedical $\beta$-Ti compositions from the literature and that measured by Inductively Coupled Plasma Optical Emission Spectrometry (ICP-OES) and LECO analyses. All compositions are in weight \% except for hydrogen (ppm).

\begin{tabular}{l|cccccccccccccc} 
Element, wt.\% & $\mathrm{Cr}$ & $\mathrm{Cu}$ & $\mathrm{Fe}$ & $\mathrm{H}(\mathrm{ppm})$ & $\mathrm{Hf}$ & $\mathrm{Nb}$ & $\mathrm{Ni}$ & $\mathrm{O}$ & $\mathrm{Ta}$ & $\mathrm{Ti}$ & $\mathrm{V}$ & $\mathrm{Zr}$ \\
\hline$[1]$ & - & - & - & - & - & 11.9 & - & 0.34 & 31 & $\mathrm{Bal}$ & 2.2 & 7.8 \\
{$[1]$} & - & - & - & - & - & 35.8 & - & 0.32 & 2.1 & $\mathrm{Bal}$ & - & 3.1 \\
{$[19]$} & - & - & - & - & - & 29.8 & - & 0.28 & 10.1 & $\mathrm{Bal}$ & - & 5.0 \\
{$[19]$} & - & - & - & - & - & 29.8 & - & 0.35 & 8.13 & $\mathrm{Bal}$ & - & 4.76 \\
{$[15]$} & - & - & - & - & - & 34 & - & 0.16 & 7 & $\mathrm{Bal}$ & - & 7 \\
This work & $<0.01$ & 0.06 & 0.03 & 22 & $<0.05$ & 36.2 & $<0.01$ & 0.26 & 1.97 & $\mathrm{Bal}$ & 0.04 & 3.16
\end{tabular}
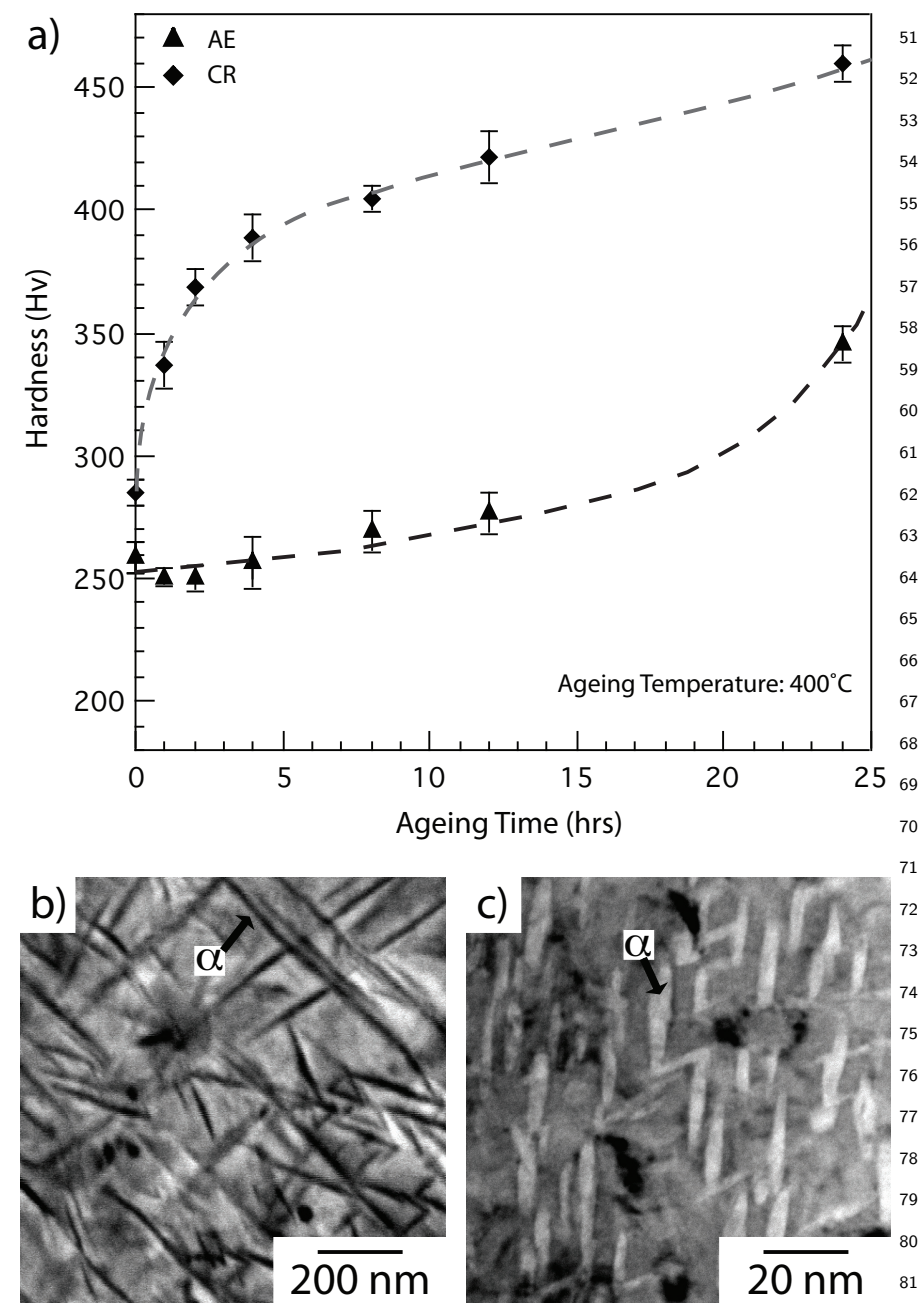

Figure 1: a) Evolution of micro-hardness of as-extruded (AE) and 83 cold-rolled (CR) Gum metal, as a function of ageing time for heat- 84 treatments between $1-24 \mathrm{~h}$ at $400^{\circ} \mathrm{C}$. Trendlines have been inserted to the data as a guide to the eye. b) Backscatter scanning electron ${ }^{85}$ microscope (BSEM) micrograph of the AE Gum metal microstructure following $24 \mathrm{~h} 400^{\circ} \mathrm{C}$ heat-treatment. c) The corresponding microstructure of the CR material with identical heat-treatment, im- ${ }^{86}$ aged by bright field transmission electron microscopy (BF-TEM). Figures adapted from [17].

derstanding of precipitate strengthening in $\beta$-Ti alloys and shed light on contradicting theories published in literature. ${ }_{91}$

The application of SANS to measure precipitation in ${ }_{92}$ engineering alloys in-situ (for example [11-14]) is infre- ${ }_{93}$ quent and, to the authors' knowledge, has never been ap- ${ }_{94}$ plied in the studies of Ti metallurgy. The bulk of SANS metallurgical research are ex-situ measurements. The experimental methodology employed in this work is similar to that of Collins et al. [11], who used in-situ SANS to study the coarsening kinetics in a nickel superalloy. To date, the experimental studies of precipitation in Ti metallurgy have been through TEM complemented by atom probe tomography and in-situ synchrotron X-ray diffraction (SXRD) [3, 9, 15, 16]. Each method has associated advantages and disadvantages. TEM remains the most important experimental method. However, these studies are ex-situ and frequently under conditions very different to the alloy's application conditions. SXRD can be employed to measure initial nucleation of phases in-situ by associating diffraction peaks to the appropriate phase [9]. SANS offers excellent insight into nano-scaled particle growth, but diffraction and scattering techniques require supporting TEM in order to be interpreted.

Two initial conditions of Gum metal were chosen to study precipitate nucleation and growth at $400^{\circ} \mathrm{C}$ by insitu SANS: (i) as-extruded Gum metal; and (ii) as-extruded $+90 \%$ cold-rolled Gum metal. These initial conditions were selected based on a study of the evolution of microhardness with ageing time and temperature, Figure 1a. It is observed that cold-rolling increases the hardness, as expected. The evolution of hardness with different ageing times at $400^{\circ} \mathrm{C}$ is significantly different in the cold-rolled material than the as-extruded. This phenomenon is due to very different precipitation behaviour in the two materials [17]. The microstructures following a $400^{\circ} \mathrm{C} 24 \mathrm{~h}$ heattreatment of both Gum metal conditions are presented in Figures $1 \mathrm{~b}$ and c. BF-TEM and BSEM techniques cannot resolve the $\omega$ phase. The $\alpha$ particles observed are an order of magnitude smaller in the CR condition, and an investigation of the precipitation mechanisms is warranted.

\section{Experimental Details}

The Gum metal studied was produced by ingot metallurgy from compacted pure elements. The furnace was back-filled with high purity argon and the elements melted by a He plasma torch. Following cooling and solidification, the ingot was inverted and remelted. This inversion and remelting process was performed three times to improve homogeneity. A $60 \mathrm{~mm}$ diameter billet was machined from the button and solution treated at $850^{\circ} \mathrm{C}$ for $60 \mathrm{~min}$. The 
billet was coated in Deltaglaze TM 3418 (Acheson, MI, USA) glass lubricant. The billet was then heat-treated at $975^{\circ} \mathrm{C}$ for $105 \mathrm{~min}$ prior to extrusion to $12 \mathrm{~mm}$ diameter rod. A section of this extruded rod was then cold-rolled to $90 \%$ strain. In this work, the as-extruded Gum metal is labelled AE, and the as-extruded $+90 \%$ cold-rolled is labelled CR, for convenience.

Pole figures previously published for $90 \%$ strain coldrolled Gum metal suggest that a $\{001\}<1 \overline{1} 0>$ texture is formed. This is in agreement with $b c c$ rolling textures in other materials [18].

The composition of the extruded bar was verified by inductively coupled plasma optical emission spectrometry (ICP-OES) and LECO analyses for the oxygen and hy-148 drogen content. This is presented in Table 1 , along with $_{149}$ a selection of similar biomedical $\beta$-Ti alloys published $\mathrm{in}_{150}$ literature. The alloy produced for this work was based ${ } n_{151}$ Saito's original publication and is in good agreement [1]. ${ }_{152}$

\subsection{Microscopy}

Specimens for optical microscopy were prepared by me-155 chanical polishing and etched using 8 vol. $\% \mathrm{HF}$ and $15^{150}$ vol. $\% \mathrm{HNO}_{3}$ in water. The initial average grain size was ${ }^{157}$ measured by analysis of the optical micrographs using the ${ }^{158}$ ImageJ software analysis package.

Specimens for TEM were removed by spark-erosion and ${ }^{160}$ thinned using twin-jet electropolishing in a solution of $8^{161}$ vol. $\% \mathrm{H}_{2} \mathrm{SO}_{4}$ in methanol at $-40^{\circ} \mathrm{C}$ and $18 \mathrm{~V}$. TEM foils ${ }^{162}$ were examined using a JEOL TEM 2000FX microscope ${ }^{163}$ and a FEI TITAN 80/300 TEM/STEM (Scanning Trans-164 mission Electron Microscopy).

The heat-treatment times studied in TEM were se-160 lected based on the SANS results, shown in Figure 8.167 The microstructures following $0.25 \mathrm{~h}, 2.5 \mathrm{~h}, 12.5 \mathrm{~h}$ and $16 \mathrm{~h}^{168}$ $400^{\circ} \mathrm{C}$ thermal exposures resulted in very different SANS ${ }^{169}$ scattering curves, warranting TEM studies, along with the ${ }^{170}$ two initial sample conditions. These heat-treatments were ${ }^{171}$ repeated in order to produce samples for microscopy, and ${ }^{172}$ all microscopy was performed ex-situ at room temperature ${ }^{173}$ following air cooling of the samples.

\subsection{X-ray Diffraction}

Laboratory XRD measurements were performed on the ${ }^{177}$ AE and CR SANS samples following the SANS experimen ${ }^{178}$ tation. XRD was performed on a PANalytical X'Pert Pro ${ }^{179}$ MPD fitted with an X'celerator detector, using $\mathrm{Cu}-\mathrm{K}_{\alpha} \mathrm{X}^{-}{ }^{180}$ ray radiation with a characteristic wavelength of $1.541 \AA a t^{181}$ $40 \mathrm{kV}$ and $40 \mathrm{~mA}$ current. Data were collected over a range ${ }^{182}$ of $20-100^{\circ} 2 \theta$ for 1 hour. Phase identification was per- ${ }^{183}$ formed using CrystalDiffract software with crystal struc- ${ }^{184}$ ture parameters of pure Ti $\alpha[29], \beta[30], \omega[31]$, and $\alpha^{\prime 1^{185}}$ [18] phases.

\subsection{Small Angle Neutron Scattering}

SANS measures the shape and intensity of the coherent ${ }_{109}$ elastic scattering at small angles from the incident beam,

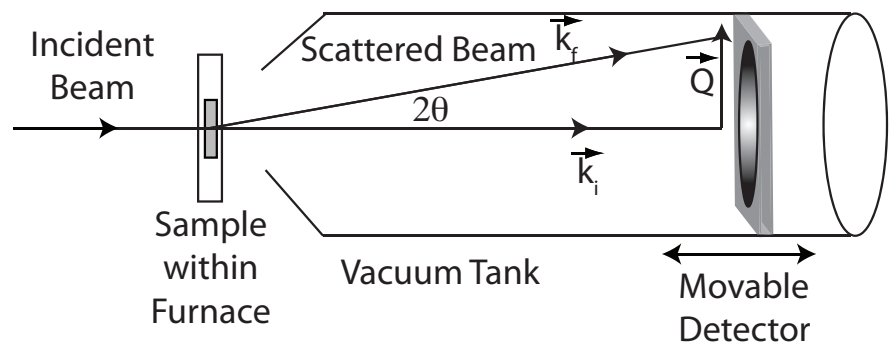

Figure 2: Schematic of the experimental arrangement used to perform small angle neutron scattering at HFIR, ORNL, Tennessee, USA.

with angles far smaller than classical diffraction angles [2027], typically under $5^{\circ}$. Thus pinhole SANS (Figure 2) can provide diffraction patterns from structures or fluctuations in composition or density on distance scales of about 1 to $100 \mathrm{~nm}$, commensurate with the size of smaller precipitates in metal alloys.

In this work, SANS was performed at Oak Ridge National Laboratory (ORNL) High Flux Isotope Reactor (HFIR) General Purpose Small Angle Neutron Scattering (GPSANS) instrument [28]. The set-up is illustrated in Figure 2. A mechanical velocity selector defines the incident neutron wavelength $\lambda=4.75 \AA$ with a $10 \%$ spread, and the beam is collimated prior to the sample by a pair of apertures. $\mathbf{k}_{\mathbf{i}}$ is the incident wave vector with magnitude $k=2 \pi / \lambda$. The scattering vector $\mathbf{Q}$ is the difference between incident and scattered wave vectors $\mathbf{Q}=\mathbf{k}_{\mathbf{f}}-\mathbf{k}_{\mathbf{i}}$. The magnitude of $Q$ quantifies the lengths of the reciprocal space $Q=\frac{4 \pi}{\lambda} \sin \theta$, where $2 \theta$ is the scattering angle.

$10 \mathrm{~mm} \times 10 \mathrm{~mm}$ square samples of the $\mathrm{AE}$ and $\mathrm{CR}$ Gum metal were ground to a thickness of $1 \mathrm{~mm}$ for experimentation, finishing with 1200 grit paper. Two SANS experiments were performed, the first on a CR sample, and the second on an AE sample under identical test conditions.

A SANS-specific argon gas atmosphere furnace was placed in the beam-line. The sample to detector distance was set at $6 \mathrm{~m}$, an aperture of $6 \mathrm{~mm}$ was used, and measurement count times were $900 \mathrm{~s}$. The $1 \mathrm{~m}$ square $8 \mathrm{~mm}$ diameter linear gas tube helium detector array was offset from the centre in the y-axis in order to measure a larger $Q$ range.

The SANS raw data was reduced to absolute scattering probabilities $\partial \Sigma(Q) / \partial \Omega$ using standard software in the HFIR Wavemetrics Igor package [28]. Data were corrected for: transmissions $T(\lambda)$ measured with the central beam stop removed and the incident beam attenuated, for backgrounds from the empty furnace, for dark current background in the detector, and with the isotropic scattering from a $3 \mathrm{~cm}$ thick Plexiglas plate for detector pixel sensitivity variations. Data were placed on the absolute scale by the ratio of the area detector count rate to the beammonitor count rate in the empty-beam transmission measurement for each wavelength.

After collecting room temperature data on each alloy 


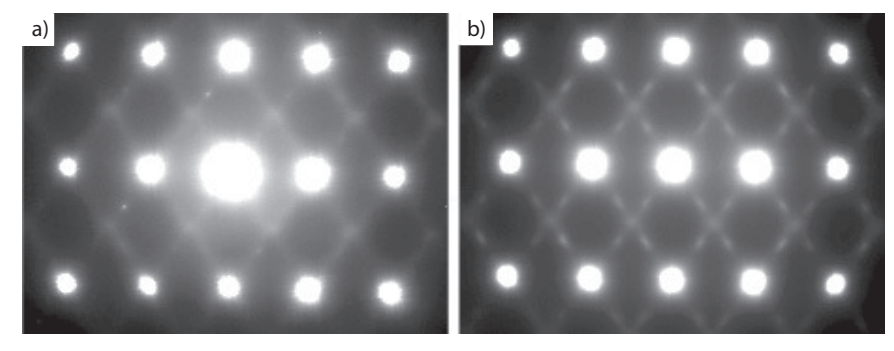

Figure 3: Gum metal TEM diffraction patterns of $\langle 110\rangle_{\beta}$ zone axis in the a) as-extruded (AE) and b) $90 \%$ cold-rolled (CR) conditions.

sample, the furnace temperature was raised to $400^{\circ} \mathrm{C}$ at $\sim$ $1^{\circ} \mathrm{C} / \mathrm{s}$, and the elevated temperature in-situ measurements were recorded every 15 minutes for $12.5-16 \mathrm{~h}$.

\section{Results}

\subsection{Microscopy}

Figure 3 shows two electron diffraction patterns from TEM for the two sample initial conditions viewed parallel to the $\langle 110\rangle_{\beta}$ zone axis. The AE pattern (Figure 3a) shows streaking along the $\{112\}_{\beta}$ which is associated with $\omega_{\text {ath }}[15,16]$. The intensity due to $\omega_{\text {ath }}$ was greater in the $\mathrm{CR}$ diffraction pattern (Figure $3 \mathrm{~b}$ ). It is reasonable to assume that the microstructure at room temperature is representative of the microstructure at $400^{\circ} \mathrm{C}$, as it is well below the beta transus temperature (typically $600^{\circ} \mathrm{C}-$ $800^{\circ} \mathrm{C}$ for metastable $\beta$-Ti alloys).

The evolution of the TEM diffraction patterns with ageing times at $400^{\circ} \mathrm{C}$ is presented in Figure 4, for both the $\mathrm{AE}$ and $\mathrm{CR}$ conditions. The longest ageing times (AE: $12.5 \mathrm{~h}, \mathrm{CR}: 16 \mathrm{~h}$ ) represent the $\mathrm{AE}$ and $\mathrm{CR}$ microstructures at the end of the SANS experiments. A key diagram is provided in Figure $4 \mathrm{~g}$ for $\omega$ and $4 \mathrm{i}$ for $\alpha$. After $0.25 \mathrm{~h}$ ageing time, the $\mathrm{AE}$ sample exhibits faint streaking in the $\{112\}_{\beta}$. Spots are seen forming after $2.5 \mathrm{~h}$ at $1 / 3$ and $2 / 3\{112\}_{\beta}$, growing in intensity after $12.5 \mathrm{~h}$ and forming more distinct spots. There are no clear spots from $\alpha$ in the diffraction pattern following the $\mathrm{AE} 12.5 \mathrm{~h}$ heattreatment, however there is a very weak suggestion this phase may be present in the $2.5 \mathrm{~h}$ pattern. TEM imaging confirmed the nanoprecipitation is predominantly $\omega$ during heat-treatment of the extruded material, and extensive $\omega$ precipitation is evident in Figure 5e. The very faint spots in some of the TEM diffraction patterns at $1 / 2\{112\}_{\beta}$ are associated with the $\alpha^{\prime \prime}$ martensitic phase, according to the schematic of Talling et al. [18]. The reflections are too weak to image this phase. Furthermore, previous imaging of this phase in deformed Gum metal has shown they are of a size greater than that measured in SANS in this work [18].

The CR material shows much less streaking in the $e_{234}$ $\{112\}_{\beta}$ at all time scales compared to the as-extruded ma- ${ }_{235}$ terial. There are distinct diffraction spots observed at $1 / 3_{236}^{235}$ and $2 / 3\{112\}_{\beta}$ after $0.25 \mathrm{~h}$ heat-treatment, that grow in $\mathrm{in}_{237}$

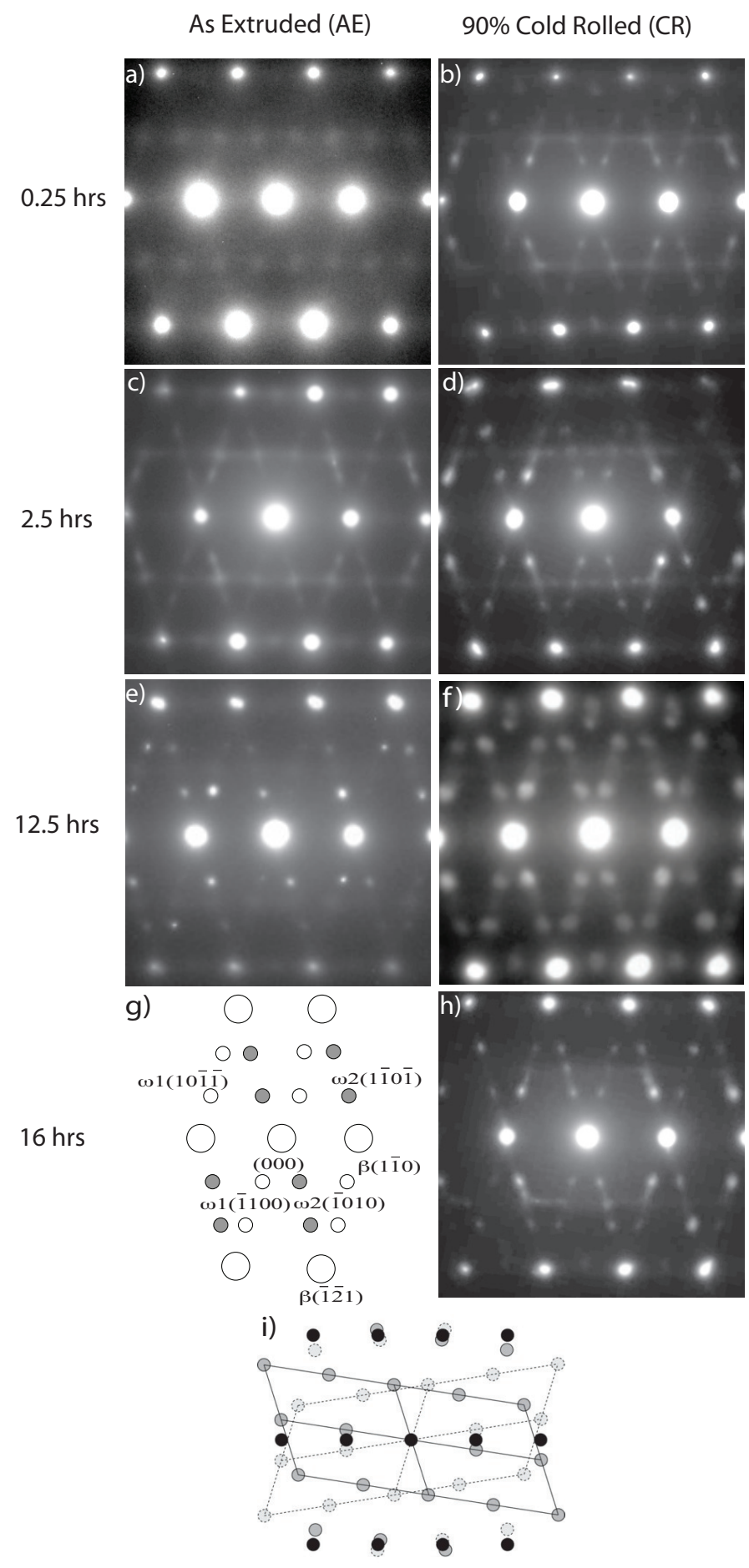

Figure 4: TEM diffraction pattern evolution for ageing times of $0.25 \mathrm{~h}-16 \mathrm{~h}$ at $400^{\circ} \mathrm{C}$ of $\mathrm{AE}$ and $\mathrm{CR}$ Gum metal. The diffraction patterns are of the $\langle 113\rangle_{\beta}$ zone axis and the reciprocal lattice streaking and spots observed at $1 / 3$ and $2 / 3\{112\}_{\beta}$ are due to the $\omega$ phase. j) Schematic. Black: $\beta$ spots; grey: $\alpha$ spots

intensity and become more distinct with prolonged thermal exposure. There is some evidence of $\alpha$ diffraction spots in the $2.5 \mathrm{~h}$ diffraction pattern (Figure $4 \mathrm{~d}$ ), and definite $\alpha$ diffraction spots in Figure $4 \mathrm{~h}$ following $16 \mathrm{~h}$ heattreatment. 

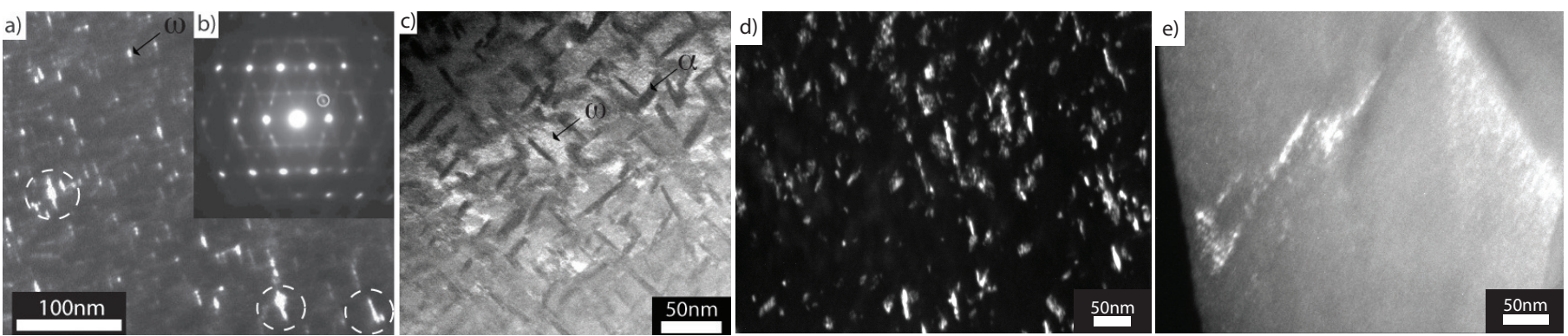

Figure 5: a) Dark-field image of cold-rolled Gum metal after $0.25 \mathrm{~h}$ ageing at $400^{\circ} \mathrm{C}$. Regions where $\alpha$ may be precipitating from $\omega$ are highlighted. b) TEM diffraction pattern on the $\langle 113\rangle_{\beta}$ zone axis for the same material as (a). The spot used to take the dark-field image (a) is highlighted. c) ADF STEM image of cold-rolled Gum metal with a $16 \mathrm{~h} 400^{\circ} \mathrm{C}$ heat-treatment. d \& e) Dark field TEM from the same $\omega$ reflection as Figure 5b of cold-rolled Gum metal with a $16 \mathrm{~h} 400^{\circ} \mathrm{C}$ heat-treatment and extruded Gum metal with a $400{ }^{\circ} \mathrm{C} 12.5 \mathrm{~h}$ heat-treatment respectively.

It was possible to obtain dark-field TEM images of the $\omega$ particles based on the $\omega$ diffraction spots for all $\mathrm{AE}$ samples with heat-treatment times at and above $2.5 \mathrm{~h}$, and CR samples of times at and above $0.25 \mathrm{~h}$. A dark-field image for $\mathrm{CR}$ material $+0.25 \mathrm{~h} 400^{\circ} \mathrm{C}$ heat-treatment is given in Figure 5a, with the $1 / 3\{112\}_{\beta}$ diffraction spot used to obtain the micrograph highlighted in Figure 5b. It is interesting to note that rods or plates may grow from the circular $\omega$ particles, highlighted in Figure 5a. Both the $\alpha$ and $\omega$ phases may be observed if their associated reflections slightly overlap, so the rods may be $\alpha$ particles. The circular $\omega$ particles range in size from approximately $3-20 \mathrm{~nm}$ after the longest heat-treatment of $16 \mathrm{~h}$ in the CR material, Figure 5d. A number of rod shaped particles are also observed.

ADF STEM-imaging of CR material after $16 \mathrm{~h}$ ageing time shows $\alpha$ particles of approximately $50 \mathrm{~nm}$ length, along with what appears to be a substantial amount of very fine particles $\sim 10 \mathrm{~nm}$ in diameter, believed to be $\omega_{\text {iso }}$, Figure 5c. Energy Dispersive X-ray (EDX) analysis of the larger precipitates showed a lowered $\mathrm{Nb}$ content, which is expected of the $\alpha$. Comparing the STEM image of Figure $5 \mathrm{c}$ to the dark field image of Figure $5 \mathrm{~d}$ from a $1 / 3\{112\}_{\beta} \omega$ diffraction spot, it is clear that extensive $\omega$ particles are in the channels between the $\alpha$ precipitates, following $16 \mathrm{~h} 400^{\circ} \mathrm{C}$ heat-treatment of the $\mathrm{CR}$ material.

\subsection{X-ray Diffraction}

XRD measurements of the CR and AE samples following SANS experimentation are presented in Figure 6a and b respectively. The CR measurement shows strong single278 $(001)_{\omega}$ and $(002)_{\omega}$ peaks. The broad high intensity peak at279 $61^{\circ}$ in the CR data appears to be a compound peak of the $(120)_{\omega}$ and the $(110)_{\alpha}$, with a single $(010)_{\alpha}$ peak at $31^{\circ} .280$ Care must be taken of the peaks observed at $50^{\circ}$ in the $\mathrm{CR}_{281}$ diffraction pattern, and at $35^{\circ}$ in the $\mathrm{AE}$ pattern. These ${ }_{282}$ peaks may arise from $\mathrm{Cu} \mathrm{K}{ }_{\beta}$ which hasn't been completely ${ }_{283}$ removed with the secondary monochromator.

There is a single $(001)_{\omega}$ peak in the AE diffraction ${ }_{28}$ pattern. $(010)_{\alpha}$ is labelled, however it is very dubious due $e_{286}$ to the peak location also lying on a $\alpha^{\prime \prime}$ peak position $\operatorname{and}_{287}$

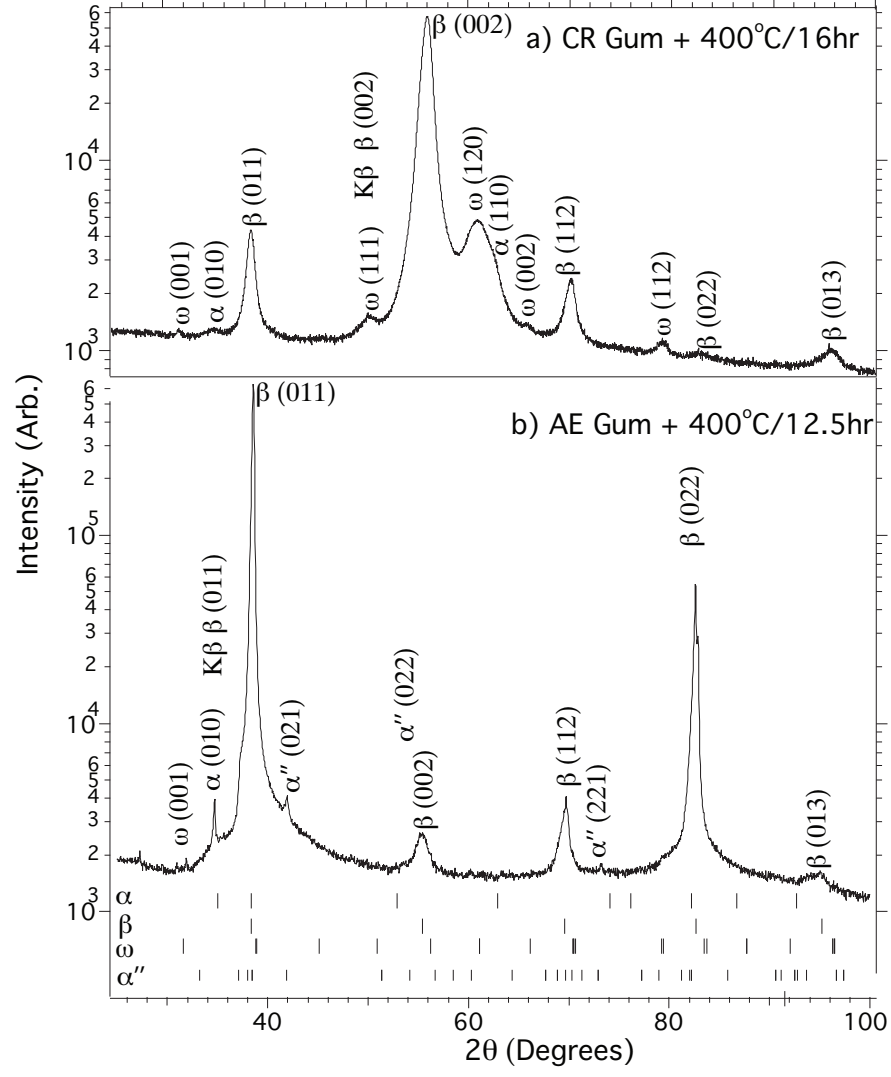

Figure 6: XRD of the $\mathrm{CR}$ and AE SANS specimens following heattreatments of (i) $400^{\circ} \mathrm{C} / 16 \mathrm{~h}$ and (ii) $12.5 \mathrm{~h}$ respectively.

the $\mathrm{Cu} \mathrm{K}_{\beta}(011)_{\beta}$ position. The $(022)_{\beta}$ is a doublet due to $K_{\alpha 1}$ and $K_{\alpha 2}$.

\subsection{Small Angle Neutron Scattering}

Examination of the raw SANS data showed that the $\mathrm{AE}$ material scattered neutrons isotropically, while the scattering from the CR material has some modest anisotropy, Figures 7 (a) and (b) respectively. The vertical lines seen in Figure $7 \mathrm{a}$ and $\mathrm{b}$ are from the different vertical detector tubes. Cold-rolling the material produces crystallographic texture in the sample [32]. Thus, the anisotropy 

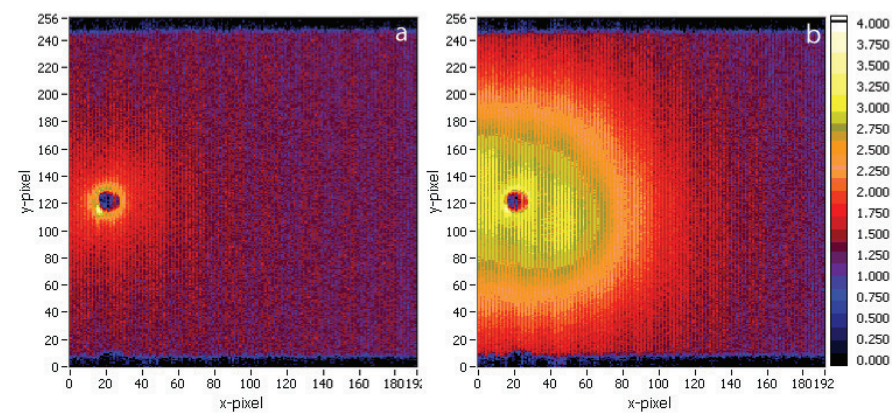

Figure 7: Raw SANS data from gas tube detector array after $7.5 \mathrm{~h}$ at $400^{\circ} \mathrm{C}$ : (a) as-extruded material, (b) cold-rolled sample.

is believed to be a consequence of particle orientation arising from texture formation due to the cold-rolling process. The thickness of the sample when mounted in the beam was normal to the rolling direction. Although in principle the anisotropy in the SANS pattern provides further information, the data was azimuthally averaged for both samples. The analysis of anisotropic patterns would add extra fitting parameters and for the disc shaped particles proposed, would require extensive numerical simulations, which would not be justified by the limited amount of extra information that might be acquired.

Selected scattering curve evolution with time and model fits are presented for both the AE and CR samples, Figure 8. The error bars have been removed as they obscure the data, but on average are $\sim \pm 0.01 \mathrm{~cm}^{-1}$.

The scattering curve evolution of the $\mathrm{AE}$ sample is markedly different to that of the CR sample, both in shape and evolution rate. The scattering curve evolution of the AE sample is slow when compared to the $\mathrm{CR}$ material, with very little change at $Q<0.01 \AA^{-1}$, and $Q>0.01 \AA^{-1}$. A broad scattering profile is seen to develop in the $\mathrm{AE}$ data, and is very apparent after $12.5 \mathrm{~h}$, between $0.01 \AA^{-1}<$ $Q<0.06 \AA^{-1}$.

The CR scattering curve evolves far more rapidly across the whole of the $Q$ range measured. The intensity at low ${ }^{328}$ $Q$ is much greater than those seen in the AE test. There is ${ }^{329}$ a clear scattering peak after $0.25 \mathrm{~h}$, i.e. the first measure- ${ }^{330}$ ment taken at $400^{\circ} \mathrm{C}$. This peak grows in magnitude and $\mathrm{d}^{331}$ shifts to lower Q up to $6.25 \mathrm{~h}$. Such peaks or maxima in ${ }^{332}$ SANS most often imply closely packed smaller particles, ${ }^{33}$ thus providing information on both particle size and inter- ${ }^{334}$ actions or spacings as discussed below. A plateau region is ${ }^{335}$ seen in the measurements after this time, shown for $12.5 \mathrm{~h}^{336}$ and $16 \mathrm{~h}$, with very slow scattering curve evolution occur- ${ }^{337}$ ring at these later times compared to earlier ones in the ${ }^{338}$ test.

\section{Discussion}

\subsection{Transmission Electron Microscopy}

The streaking along the $1 / 3$ and $2 / 3\{112\}_{\beta}$ observed $_{345}$ in both initial conditions (Figure 3 ) is associated with $\omega_{\text {ath }}{ }^{346}$

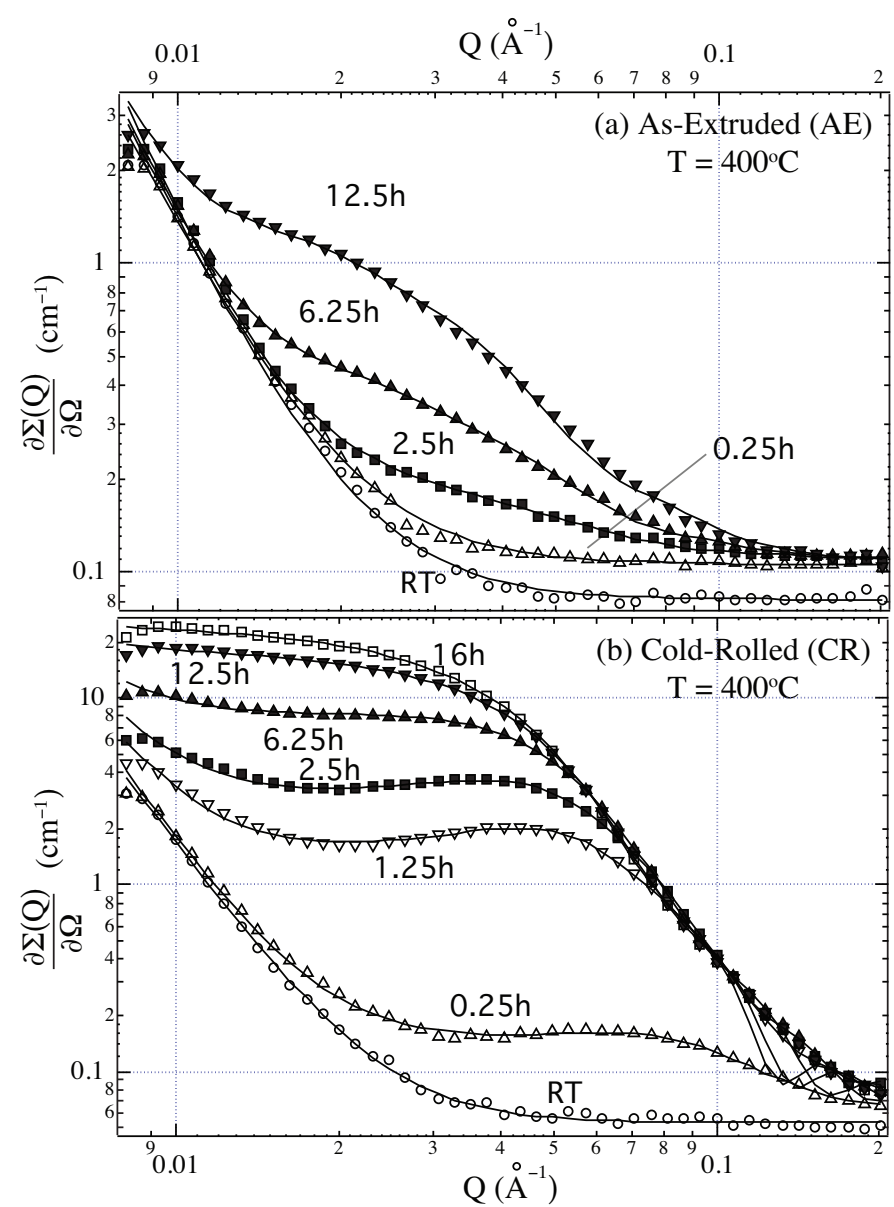

Figure 8: The evolution of SANS scattering curves with time measured in-situ at $400^{\circ} \mathrm{C}$ for (a) as-extruded Gum metal (AE), and (b) as-extruded + cold-rolled Gum metal (CR), plotted on a log-log scale. The times represent the time at which the measurement was finished, with each measurement taking $0.25 \mathrm{~h}$. Solid lines are fits to the data which include monodisperse discs. Poor fits at high $\mathrm{Q}$ for $t \geq 6.25 \mathrm{~h}$ in the $\mathrm{CR}$ condition can be improved with a polydisperse disc model.

within the $\beta[15,16]$. The greater intensity in the CR material suggests that $\omega_{\text {ath }}$ is enhanced as a consequence of plasticity. During thermal exposure at $400^{\circ} \mathrm{C}$, the streaking is seen to shift to distinct spots at $1 / 3$ and $2 / 3\{112\}_{\beta}$ in both materials (Figure 4), due to completion of the $\{111\}_{\beta}$ plane collapse. This $\omega$ phase is termed $\omega_{\text {iso }}$, and is due to diffusion induced chemical rearrangement of atomic species. The kinetics appear to be much more rapid in the $\mathrm{CR}$ material than the AE material. The reason for this may be two fold: (i) there is greater $\omega_{\text {ath }}$ initially present in the CR material; (ii) the CR material possesses a greater dislocation density. These may act as further $\omega$ nucleation sites, and also act as fast diffusion paths.

$\alpha$ particles appear to grow from the $\omega_{\text {iso }}$ phase, seen in the dark-field TEM micrograph in Figure 5a. This has been observed previously in Gum metal [15], and in Ti5553 [16]. However, this conclusion must be treated with caution, as the two precipitates do not necessarily lie in the same plane, and could simply be above one another within 
the thickness of the foil. Also, as mentioned previously, it is not possible to define a phase based on precipitate shape alone.

The TEM diffraction patterns and the dark-field imaging give strength to the suggestion that precipitation occurs in the following order: $\beta \rightarrow \beta+\omega_{\text {ath }} \rightarrow \beta+\omega_{\text {iso }} \rightarrow$ $\beta+\alpha$, when heat-treated above the $\beta$ solvus, quenched, ${ }_{400}^{399}$ and subsequently aged at $400^{\circ} \mathrm{C}$. $\beta$ in this case refers to ${ }_{401}$ the $b c c$ phase in general, as we have no specific evidence in the present case to support the decomposition of the $\beta ._{403}$

It is notable when performing the TEM that both $\omega_{\text {ath }}{ }_{404}$ and $\omega_{\text {iso }}$ nucleation were far more localised in the $\mathrm{AE} \mathrm{ma-}{ }_{405}$ terial than the CR material, evident on comparison of Fig- ${ }_{-}{ }^{405}$ ures $5 \mathrm{e}$ and $5 \mathrm{~d}$ respectively. The $\mathrm{CR} \omega$ was generally quite ${ }_{407}$ evenly distributed through the grains in all heat-treatment conditions. This is not true for the AE material, where the $\omega$ particles were present in localised regions of certain ${ }_{410}^{409}$ grains in all heat-treatment conditions, Figure 5e. The diffraction patterns presented in Figure 4 were selected $\mathrm{as}_{412}{ }_{411}$ they illustrate the $\omega$ evolution, however it is possible to image areas with very little $\omega$ reflections in the AE material. If the $\omega$ particles provide precipitate strengthening it is desirable that they are evenly distributed through the ${ }^{413}$ grain, as is the case for the CR material.

It was observed that when comparing STEM to dark-415 field TEM that the area fractions of the precipitates are ${ }^{416}$ markedly different. It is impossible to make estimates or ${ }^{417}$ comparisons of $\omega$ volume fraction based on dark-field TEM ${ }^{418}$ imaging for a number of reasons, namely: (i) the image is ${ }^{419}$ based on just one lattice reflection; (ii) the thickness of the ${ }^{420}$ sample will contribute to the area fraction of particles ob-421 served; and (iii) the image area is an area of one grain and ${ }^{422}$ may not be representative of the bulk material. The inability to compare the extent of nano-precipitation by TEM methods is reason to attempt in-situ SANS measurements of the precipitation process. The TEM studies described are used as a guide to the modelling and interpretation of the SANS data.

\subsection{X-ray Diffraction}

The $\omega$ phase is not easily detected by laboratory XRD. The clear peaks from the CR material after $16 \mathrm{~h}$ thermal exposure are evidence of extensive $\omega$ precipitation. The strong peak at $(002)_{\beta}$ arises from the cold-rolling process. The AE material produces much weaker diffraction from the particles and are difficult to identify from background, implying that the nanoparticles have a much lower volume fraction compared to the CR material.

\subsection{Small Angle Neutron Scattering Modelling}

A number of software programs exist to facilitate least squares fits to SANS data, notably the NIST SANS pack- ${ }^{423}$ age used with Wavemetrics Igor Pro [33], FISH developed ${ }^{424}$ at ISIS [34] (used in this work), and SASVIEW [35].
The probability of small angle neutron scattering from uniform monodisperse particles is

$$
\frac{\partial \Sigma(Q)}{\partial \Omega}=N V^{2}(\Delta \rho)^{2} P(Q) S(Q)+\mathrm{BKG}
$$

where $N$ is the number of particles per unit volume, $V$ is the volume of one particle, and $P(Q)$ is the particle form factor or shape function. Note that the dispersed particle volume fraction $\phi=N V . P(Q)$ depends on the size and shape of the particle and is normalised such that $P(Q=0)=1.0[36] . S(Q)$ is the interparticle structure factor, which tends to 1.0 for sufficiently dilute systems, but otherwise allows for interparticle interactions. BKG is any residual background not allowed for in the data reduction, often a flat term for incoherent scattering from certain elements, such as hydrogen. $\Delta \rho=\rho_{\text {ppt }}-\rho_{\text {matrix }}$ is the neutron scattering length density difference between the particle and its matrix. The scattering length density of phase $x$ is

$$
\rho_{x}=\left(\rho_{\text {mass }} N_{A} / M_{r}\right) \Sigma n_{i} b_{i}
$$

where $\rho_{\text {mass }}$ is the phase mass density, $N_{A}$ is Avogadro's number, $M_{r}$ is the molecular weight of the phase, $n_{i}$ is the atomic fraction of element $i$ in the phase, and $b_{i}$ is that element's associated neutron scattering length. A few isotopic species, including $\mathrm{H}$ and $\mathrm{Ti}$, have negative scattering lengths. Unlike X-rays where scattering is proportional to atomic number, neutron scattering lengths vary erratically across the periodic table, so it is not immediately apparent which phases have strong neutron scattering contrast relative to the matrix in the alloy studied here.

The general form of $P(Q)$ is given by van de Hulst's equation [37]

$$
P(Q)=\frac{1}{V^{2}}\left|\int_{0}^{V} \exp [i f(Q \alpha)] d V\right|
$$

where $\alpha$ is a "shape parameter". Analytical expressions exist for most common shapes and more complex shapes can be deduced from these. Taking the case of rod (or disc) shaped particles of length $L$ and radius $R$, the form factor is given by

$$
P(Q)=\int_{0}^{\pi / 2} F^{2}(Q) \sin (\gamma) d \gamma
$$

where

$$
F(Q)=\frac{\sin \left(\frac{1}{2} Q L \cos \gamma\right)}{\frac{1}{2} Q L \cos \gamma} \frac{2 J_{1}(Q R \sin \gamma)}{Q R \sin \gamma}
$$

in which $J_{1}(x)$ is the first order Bessel function, and the equation requires numerical integration over angle $\gamma$ between the $Q$ vector and the angle of the $\operatorname{rod}[34,38]$.

At higher volume fractions, interference from waves scattered by adjacent particles occurs, and is accounted for by the interparticle structure factor $\mathrm{S}(\mathrm{Q})$. The simplest 
structure factor is for impenetrable hard spheres, for which 469 the Percus-Yevick approximation was solved analytically 470 by Ashcroft and Lekner [39]. As the hard sphere volume 471 fraction increases $S(Q)$ pushes down the SANS intensity at 472 small Q, eventually giving a peak at approximately $2 \pi$ di-473 vided by the mean particle separation. $\mathrm{S}(\mathrm{Q})$ always tends 474 to 1.0 at high $\mathrm{Q}$.

Ashcroft and Lekner derived $\mathrm{S}(\mathrm{Q})=1 /(1-\mathrm{C}(\mathrm{Q}))$ where 476 $C(Q)$ is an expression containing the volume fraction $\left(V_{H S}\right)_{477}$ and diameter $(D)$ of the hard spheres.

$$
\begin{aligned}
C(Q)= & -\frac{24 V_{H S}}{(Q D)^{6}}\left\{\alpha(Q D)^{3}(\sin Q D-Q D \cos Q D)\right. \\
& +\beta(Q D)^{2}\left[2 Q D \sin Q D-\left(Q^{2} D^{2}-2\right) \cos Q D\right. \\
& -2]+\gamma\left[\left(4 Q^{3} D^{3}-24 Q D\right) \sin Q D-\left(Q^{4} D^{482}\right.\right. \\
& \left.\left.\left.-12 Q^{2} D^{2}+24\right) \cos Q D+24\right]\right\}
\end{aligned}
$$

and $\alpha=\left(1+2 V_{H S}\right)^{2} /\left(1-V_{H S}\right)^{4}, \beta=-6 V_{H S}\left(1+\frac{V_{H S}}{2}\right)^{2} /(1-484$ $\left.V_{H S}\right)^{4}, \gamma=\frac{1}{2} V_{H S}\left(1+2 V_{H S}\right)^{2} /\left(1-V_{H S}\right)^{4}$.

In order to deduce microstructural parameters from the ${ }_{486}$ reduced SANS scattering curves (Figure 8), FISH [34] was ${ }_{487}$ employed to produce a model that fits to the data. Vari- ${ }_{488}$ ous combinations of particle shapes were used, based upon $_{489}$ TEM, and a successful model combination was found. Dis- 490 cussing the model in its constituent parts:

a) Background BKG. A small flat background was included ${ }_{492}$ to account for incoherent scattering, which varies a little ${ }_{493}$ with temperature.

b) Porod Scattering $a Q^{-4}$. The Porod limit [40] shows $_{495}$ that for a smooth particle with sharp interfaces the inten- ${ }_{496}$ sity decreases proportional to $Q^{-4}$ at high $Q$

$$
I(Q)_{Q \rightarrow \infty}=2 \pi S(\Delta \rho)^{2} Q^{-4}
$$

where $\mathrm{S}$ is the surface area per unit volume. The power ${ }^{500}$ term was initially left as a fitting parameter, as values ${ }^{501}$ towards -3 indicate rough or fractal interfaces, but here ${ }^{502}$ it always tended towards -4 , so was left fixed, reducing ${ }^{503}$ the number of fitting variables. $a=2 \pi S(\Delta \rho)^{2}$ is a fit- ${ }^{504}$ ting parameter in the model. Large micron sized grains ${ }^{505}$ were observed in the as-extruded material by optical mi- ${ }^{506}$ croscopy, thus the Porod scattering potentially arose from ${ }^{507}$ the interfaces of these larger particles, which would create ${ }^{508}$ a scattering peak at a lower Q than that resolvable in this ${ }^{509}$ measurement. c) $\mathrm{P}(\mathrm{Q})$ Discs. From TEM (Figure 5), the scattering ob-511 served could be due to the $\omega$ phase, $\alpha$ phase, or both, de-512 pending on the processing condition and thermal exposure ${ }^{513}$ times. These have circular or rectangular 2-dimensional514 shape respectively when viewed in TEM. There is a va-515 riety of three dimensional shapes that correspond to the ${ }^{516}$ $2-\mathrm{D}$ projections observed in micrographs. For example,517 the observed $\omega$ circle may correspond to a disc, sphere, ${ }^{518}$ lenitcular-shape [15] etc. A model of randomly oriented ${ }^{519}$ discs gave best agreement with the SANS data. Though 520 this may not be a unique interpretation, it is supported ${ }^{521}$

by the TEM images. A schematic defining the disc radius $(\mathrm{R})$ and length $(\mathrm{L})$ is inset in Figure 10a.

d) S(Q) Hard Spheres (HS). As previously discussed, with higher volume fractions, scattering due to interparticle interference arises. This is accounted for using the hard sphere interparticle structure factor that multiplies the form factor for randomly oriented discs. The HS model is only an approximation for non-spherical particles in a metal alloy, but it is a reasonable one for modest aspect ratio particles at modest volume fractions, without interpreting the fitted values of the hard sphere radius and hard sphere volume fraction too literally. At very high volume fractions preferred orientations of anisotropic particles become important, requiring complex numerical simulations.

The full model is therefore described by

$$
\partial \Sigma(Q) / \partial \Omega=P(Q)_{\mathrm{Discs}} S(Q)_{\mathrm{HS}}+a Q^{-4}+\mathrm{BKG}
$$

where $P(Q)_{\text {Discs }}$ is given by Equation 4 and $S(Q)_{\mathrm{HS}}$ by Ashcroft and Lekner [39], discussed previously. $P(Q)_{\text {Discs }}$ has three fitting parameters: scale (a fitting parameter particular to FISH equal to $\left.10^{-24} \phi(\Delta \rho)^{2}\right)$, disc radius $R$, and disc length $L$. If the scattering contrast $(\Delta \rho)^{2}$ is known, the volume fraction $\phi$ can be determined from the scale factor or vice-versa. $S(Q)_{\mathrm{HS}}$ has two fitting parameters, the hard sphere radius $R_{\mathrm{HS}}$ and the hard sphere volume fraction $V_{H S}$. Though this may be an effective approximation for non-spherical particles, the hard sphere volume fraction should be similar to that from $P(Q)_{\text {Discs }}$ in a good fit. The final fitting parameter is $a$ of the Porod scattering. Thus, the model is composed of just 6 fitting parameters in total, all of which have physical meaning. Initial estimates of these parameters are introduced into the model, and the model fit converges to the least squares minimum with the data by the Marquadt method.

An example of the full model fit to a SANS measurement of the cold-rolled sample after $t=1.25 \mathrm{~h}$ at $T=$ $400^{\circ} \mathrm{C}$ is shown in Figure 9. This figure also shows the contribution of each component of the model. The fits show good agreement for the RT measurements of both the AE sample and CR sample, and can be fitted with just Porod scattering + BKG. This is illustrated on comparing the shape of the curve $a Q^{-4}+$ BKG in Figure 9 to the RT scattering curve (Figure $8 \mathrm{a}$ and $\mathrm{b}$ ). There is perhaps a suggestion of a very small peak at $Q \sim 0.035 \AA^{-1}$ in both room temperature measurements (Figure $8 \mathrm{a}$ and b), but it was decided not to over fit the data. From the electron diffraction patterns, there are evidently fine $\omega$ particles present in both initial conditions, seen as streaking along the $\{112\}_{\beta}$ in Figure $3 a$ and b. $\omega_{\text {ath }}$ has the same composition as the $\beta$ matrix [7] and thus has no neutron scattering contrast. This explains why no scattering peak is observed initially, even though $\omega$ particles are clearly present in the TEM diffraction patterns.

A scattering peak forms immediately in the cold-rolled sample during thermal exposure at $400^{\circ} \mathrm{C}$ (Figure $8 \mathrm{~b}$ ), but not in the as-extruded sample (Figure 8a), which can still 
be fitted with a Porod + BKG curve shape at $t=0.25 \mathrm{~h}$. Following this, it is not possible to accurately fit the data without the form factor $P(Q)$. The scattering peaks that form in both SANS experiments are due to the formation of a phase with a different composition to the matrix. The as-extruded data did not require a structure factor term to fit the data, indicating a lower volume fraction.

The model fits were not as good at high $Q$ at later time scales, in both experiments. The slight fitting error that occurs can be corrected by accounting for polydispersity in the model (effectively smoothing the peak shape at high $Q)$. The form factor used in FISH is for a monodisperse system. SASVIEW was used to confirm that polydispersity improves the model fit, and there was good agreement of mean particle size between the models.

The model fit results illustrating the evolution of disc radius, length, and $\phi(\Delta \rho)^{2}$ during thermal exposure are shown in Figures 10a - c. The physical shapes of the discs are different in the CR and AE samples, Figure 10a. From $1 \rightarrow 16 \mathrm{~h}$ the $\mathrm{CR}$ has a length to diameter ratio $L / 2 R \sim 0.45$, while the ratio for the AE sample between $3.5 \rightarrow 12.5 \mathrm{~h}$ is $L / 2 R \sim 0.2$. The growth of the average particle size appears to be quite similar, between $1-12.5 \mathrm{~h}$ the particle radius increases by $2 \mathrm{~nm}$ and length by $1.5 \mathrm{~nm}$, while the AE average radius increases by $1.6 \mathrm{~nm}$ and the length increases by $2 \mathrm{~nm}$, respectively. It is important to reiterate that these values are based on the assumption that scattering is arising from a single size distribution of disc-shaped precipitates. It is justifiable to state these disc-shaped dimensions producing scattering correspond to the $\omega$ phase for the extruded data based on TEM, however the cold-rolled sample also nucleates extensive $\alpha$ so

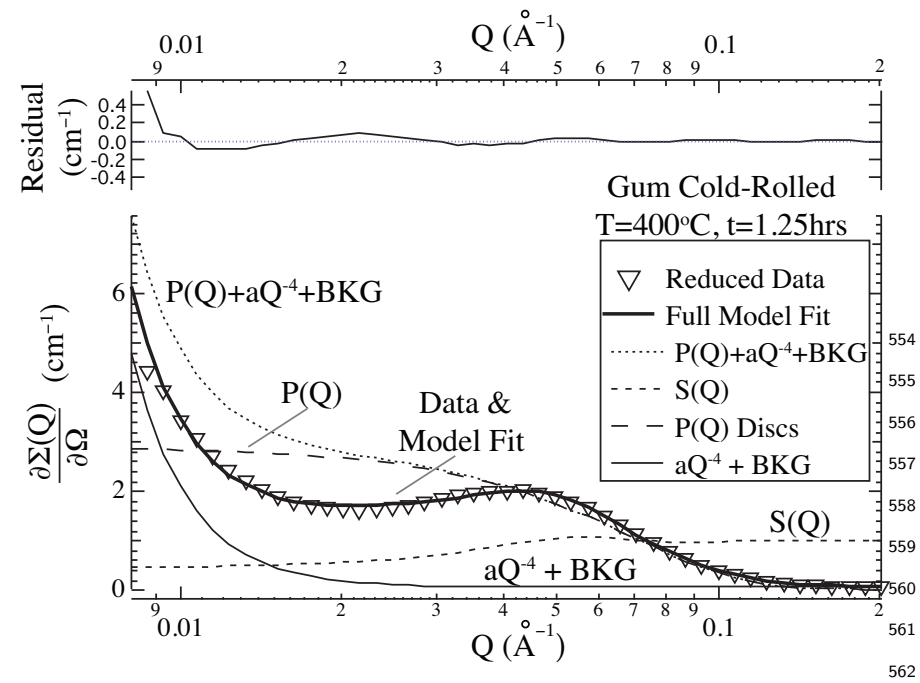

Figure 9: An example of the SANS model fit used in this work for ${ }^{563}$ the cold-rolled Gum metal at $t=1.25 \mathrm{~h}$ during thermal exposure ${ }^{564}$ at $T=400^{\circ} \mathrm{C}$. $Q$ is plotted on a $\log$ axis. The graph illustrates 565 the components of this model, where the overall model fit is defined ${ }_{566}$ as $P(Q) S(Q)+a Q^{-4}+\mathrm{BKG}$. The scattering from $\mathrm{S}(\mathrm{Q})$ is further illustrated by comparing the full model fit to the fit of $P(Q)+a Q^{-4}+{ }^{567}$ $\mathrm{BKG}$ i.e. by comparing to a fit with no scattering factor.

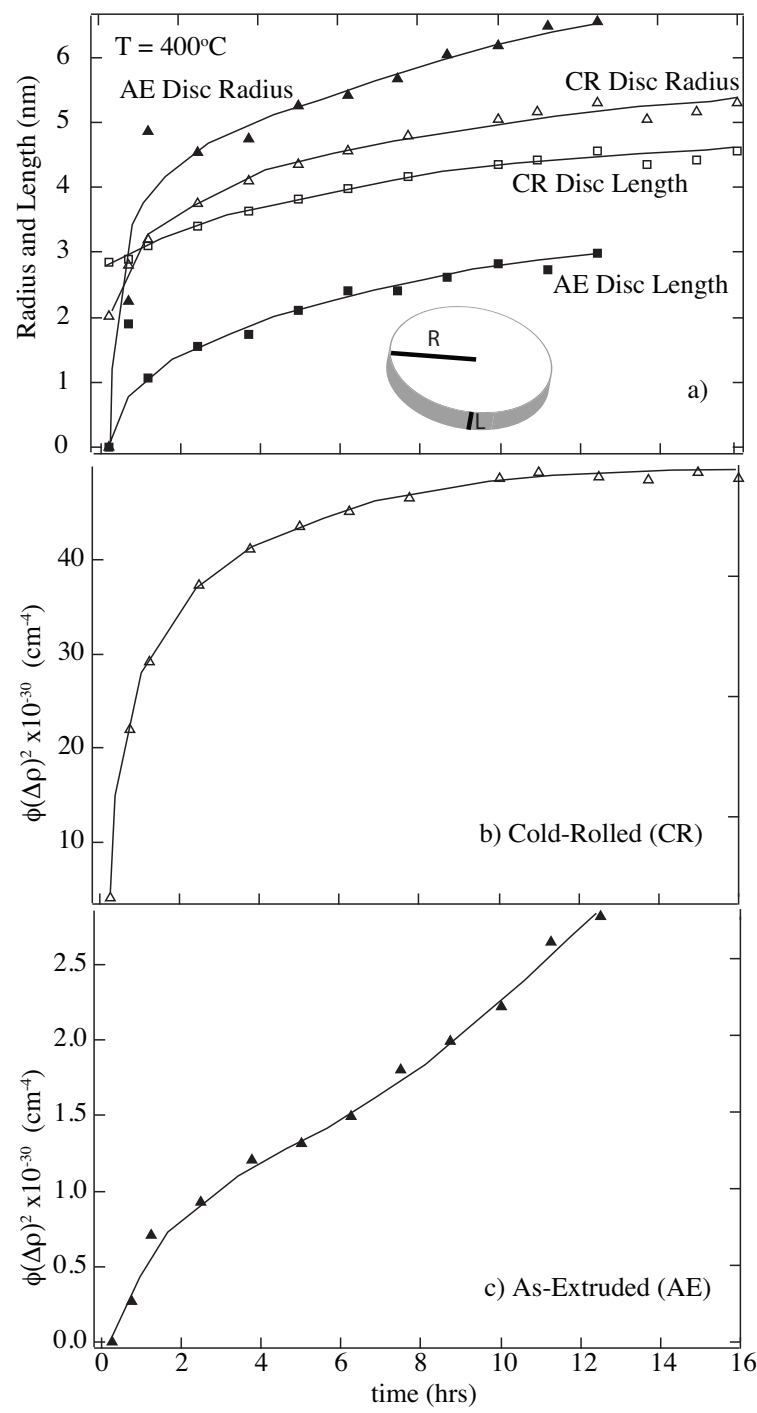

Figure 10: SANS model fit results for in-situ measurements during $400^{\circ} \mathrm{C}$ thermal exposure on an as-extruded (AE) and cold-rolled (CR) sample. a) Disc radius and length of both processing conditions. b and c) Cold-rolled and as-extruded $\phi(\Delta \rho)^{2}$ term respectively. The curves through the data points are guide for the eye fits. Inset a) Schematic defining the disc radius $(\mathrm{R})$ and length $(\mathrm{L})$.

the SANS model may be too simple to represent the coldrolled data. As a unimodal model fits the data well, it would likely be fruitless to pursue a multimodal model that wouldn't simply be overfitting to the data.

Subtracting the hard-sphere diameter from either the particle diameter or length should give an approximation to an interparticle distance of the system. The interparticle distances are $\lambda_{d} \sim 8 \mathrm{~nm}$ for $\mathrm{CR}+6.25 \mathrm{~h}$ heat-treatment (where the structure factor is apparent), and $\lambda_{d} \sim 20 \mathrm{~nm}$ for $\mathrm{AE}+6.25 \mathrm{~h}$ heat-treatment. These values seem reasonable, but again care must be taken when interpreting the cold-rolled material data.

The SANS data shows that the magnitude and evolution of the term $\phi(\Delta \rho)^{2}$ are dramatically different between the $\mathrm{CR}$ and $\mathrm{AE}$ cases, Figure $10 \mathrm{~b}$ and c. It is evident that 
particle evolution and growth during thermal exposure is62 far more rapid in the CR material than the AE material.627 As previously discussed this is most likely due to the $\mathrm{CR}_{628}$ material possessing a higher initial number density of $\omega_{\text {ath }}{ }^{629}$ and a greater dislocation density.

From Equation 5, it is clear that the volume fraction $\phi_{631}$ can only be deduced from the SANS model if the scatter-632 ing length density contrast $\Delta \rho$ is known. A Fortran model633 was developed which took the $\phi(\Delta \rho)^{2}$ term as input for 634 each thermal exposure. The initial model used the aver-635 age phase compositions from an atom-probe composition6з profile published by Nag et al. in a very similar alloy as637 input [15]. The scattering length of each element in the alloy is $b_{\mathrm{Ti}}=-3.4382 \times 10^{-5} \AA, b_{\mathrm{Nb}}=7.0543 \times 10^{-5} \AA, 639$ $b_{\mathrm{Zr}}=7.1630 \times 10^{-5} \AA$, and $b_{\mathrm{Ta}}=6.91703 \times 10^{-5} \AA[41] .640$ Each phase's mass density $\rho_{\text {mass }}$ and molecular weight $M_{r 641}$ were calculated from first principles, based on the atomic 642 weights and densities of each element in each phase and ${ }_{643}$ the atomic fraction in each phase from Nag [15], and thus644 the scattering length densities of each phase $\rho_{x}$ were cal-645 culated from Equation 2. This allowed for volume frac-646 tions to be outputted, Equation 5. The model incorpo-647 rated a check for conservation of matter (i.e. the lever 648 rule). According to Nag et al. the $\alpha$ phase is initially649 depleted in $\mathrm{Ti}$ [15], and the scattering length densities650 calculated from this work are $\rho_{\beta}=-0.27 \times 10^{10} \mathrm{~cm}^{-2}{ }_{6,61}$ $\rho_{\alpha}=0.24 \times 10^{10} \mathrm{~cm}^{-2}, \rho_{\omega}=-0.73 \times 10^{10} \mathrm{~cm}^{-2}$. Based on652 this work the absolute values of the scattering length den-653 sity contrast of each phase with the matrix are very similar:654 $\left|\rho_{\omega-\beta}\right|=0.46 \times 10^{-10} \mathrm{~cm}^{2}$ and $\left|\rho_{\alpha-\beta}\right|=0.51 \times 10^{10} \mathrm{~cm}^{-2} .655$ Applying this methodology to the monodisperse disc650 model gives a reasonable volume fraction $\phi$ for the $\mathrm{AE}_{657}$ data (13\% after $12 \mathrm{~h}$ heat treatment) for the $\omega$ phase, how-658 ever the CR data reaches $240 \%$ after $16 \mathrm{~h}$ heat treatment.659 The sensitivity of the model to $\mathrm{Ti}$ and $\mathrm{Nb}$ distributions660 between phases was checked, and shown to be extremely661 sensitive. Altering the $\mathrm{Ti}$ and $\mathrm{Nb}$ in each phase by 5 at.\%662 (i.e. further depleting the $\omega_{\text {iso }}$ phase of $\mathrm{Nb}$ ) from the val-663 ues published by Nag et al. [15] decreases the predicted volume fraction by an order of magnitude.

From the earlier discussion of the TEM diffraction patterns it is justifiable that scattering arises due to the $\omega$ phase alone in the AE material. The $\mathrm{CR}$ analysis cannot be so conclusive due to $\alpha$ spots also present in the final TEM diffraction pattern. The XRD provides evidence that extensive amounts of $\omega$ and $\alpha$ are present in the CR material after $16 \mathrm{~h}$ heat treatment. Various SANS models were tried for the cold-rolled data based on the $2 \mathrm{D}$ micrographs that might better represent the microstructures, including platelets and rods with initial inputs of $L=50 \mathrm{~nm}$ to check for convergence, however a satisfactory model was not found. The fact that disc shaped particles fit the cold-rolled data so well is not conclusive evidence that the scattering observed is arising from the $\omega$ phase alone. The $\alpha$ particles have similar width to the SANS model output diameters. Due to a number of reasons including i) scattering anisotropy arising from particle orientation, ii) possibly similar scattering length density contrasts of the two phases of interest, iii) and that a simple unimodal model fits the data so well, it may not be possible to produce a satisfactory SANS model for the complicated case of co-precipitation of $\omega$ and $\alpha$ in the cold-rolled material.

As $\mathrm{Nb}, \mathrm{Zr}$, and Ta all have similar scattering lengths, and the atomic fraction of $\mathrm{Zr}$ and $\mathrm{Ta}$ are low in this alloy (2 at.\% and 1 at.\% respectively), it is possible to treat the alloy as a binary Ti-Nb system for the SANS data analysis. The Fortran model was developed to iteratively alter the composition of $\mathrm{Ti}$ and $\mathrm{Nb}$ in each phase away from the initial bulk value and output the corresponding volume fraction of $\omega_{\text {iso }}$ for each value of $\phi(\Delta \rho)^{2}$ for all thermal exposure times. A graph of this iterative approach is shown in Figure 11, plotting the difference in atomic fraction of $\mathrm{Nb}$ between phases and the corresponding model prediction of $\omega_{\text {iso }}$ volume fraction for each thermal exposure. It was observed that conservation of matter and realistic volume fractions (based on earlier TEM observations) are only obtained by continuously increasing $n_{\mathrm{Nb}, \beta}-n_{\mathrm{Nb}, \omega}$ with increasing thermal exposure times. It also appears from this plot that the depletion of $\mathrm{Nb}$ in the $\omega_{\text {iso }}$ phase $\left(n_{\mathrm{Nb}, \beta}-n_{\mathrm{Nb}, \omega}\right)$ and the volume fraction of $\omega$ are both far greater in the cold-rolled material than the as-extruded material. It is reasonable to believe that the actual values of $n_{\mathrm{Nb}, \beta}-n_{\mathrm{Nb}, \omega}$ and $\omega_{\text {iso }}$ volume fraction lie in the regions of highest slope, where there is a balance between sensible values for each term. For the $12.5 \mathrm{~h} \mathrm{AE}$ condition, this corresponds to approximately $n_{\mathrm{Nb}, \beta}-n_{\mathrm{Nb}, \omega}=7-11$ at. $\%$, $\phi_{\omega}=7-20 \%$, and $n_{\mathrm{Nb}, \beta}-n_{\mathrm{Nb}, \omega}=17-26$ at. $\%, \phi_{\omega}=22-$ $50 \%$ for the $16 \mathrm{~h} \mathrm{CR}$ condition. For the case of the CR material this is not conclusive as the nanoscale $\alpha$ may be contributing to the SANS measurement.

There are two possible methods that could be pursued in order to deduce the volume fraction from this experiment more accurately. The first is to perform atom-probe measurements on $\mathrm{AE}$ and $\mathrm{CR}$ Gum metal with different HT times at $400^{\circ} \mathrm{C}$. This would measure the composi-

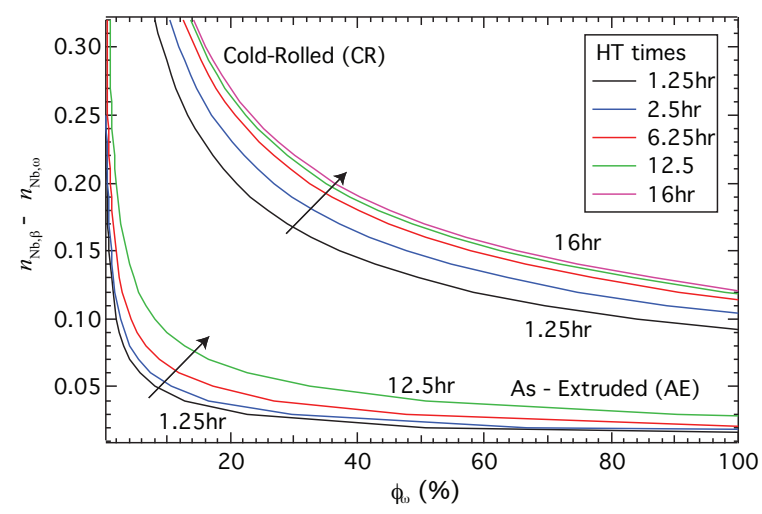

Figure 11: Variation of fitted $\omega$ molar fractions $\phi_{\omega}$ with difference of $\mathrm{Nb}$ at.\% between matrix and precipitate at different thermal exposures for the as-extruded (AE) and cold-rolled (CR) material, deduced from values of $\phi(\Delta \rho)^{2}$. 
tion evolution in each phase due to the thermal exposure.719 However this technique is very localised, and may not nec-720 essarily be representative of the overall alloy. The second 721 is to perform interrupted Small Angle X-Ray Scattering (SAXS) measurements, and by comparison of the SAXS and SANS data, one may be able to determine a value for ${ }_{72}$ $\Delta \rho[42]$. Both of these are beyond the scope of the current $7_{22}$ paper.

It is interesting to note that the evolution of the $\phi(\Delta \rho)^{2}{ }_{727}$ term for the cold-rolled and as-extruded sample (Figure 22 10) show similarities to the hardness measurements trend-729 lines (Figure 1). The micro-hardness of the as-extruded 730 sample increases quite linearly $\sim 250-280 \mathrm{Hv}$ between ${ }_{731}$ $0-12.5 \mathrm{~h}$, while the cold-rolled micro-hardness increases 732 quite dramatically from $\sim 280-400 \mathrm{Hv}$ in the first $6 \mathrm{~h}, 733$ after which it plateaus. Thus, the large increase in the ${ }_{734}$ CR micro-hardness may correspond to the large increase 735 in the $\phi(\Delta \rho)^{2} \mathrm{CR}$ term, while a small increase in $\mathrm{AE}_{736}$ micro-hardness may correspond to the small increase in $_{737}$ the $\phi(\Delta \rho)^{2}$ AE term. Jones et al. [17] suggest that $\omega$ leads7з to the rapid formation of fine scale $\alpha$ precipitates and атзя resulting increase in hardness. This work suggests that,740 although fine scale $\alpha$ is present in the cold-rolled material ${ }_{741}$ (Figures 5), the rapid increase in hardness may be due to742 rapid isothermal $\omega$ formation at $400^{\circ} \mathrm{C}$, in agreement with ${ }_{743}$ Ikeda [43].

\section{Conclusions}

An in-situ SANS measurement studying phase nucle-748 ation and growth in a Ti alloy during thermal exposure 749 has been successfully performed for the first time at the 750 GP-SANS at ORNL HFIR. Specimens of Gum metal with ${ }_{751}$ different processing routes were studied, one specimen was752 as-extruded, the other was as-extruded followed by $90 \%$ cold-rolled. The processing route is shown to dramatically alter particle evolution during thermal exposure at $400^{\circ} \mathrm{C}$. $^{753}$

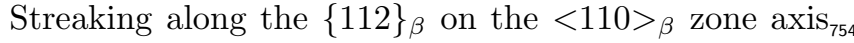
shows that athermal $\omega$ was initially present in both sam-755 ples, (Figure 3). The intensity was greater in the cold-756 rolled material, suggesting the athermal phase is induced 757 during deformation.

Ex-situ TEM studies illustrate that isothermal $\omega$ was $^{759}$ present after just $0.25 \mathrm{~h}$ in the cold-rolled material when ${ }^{760}$ heat-treated at $400^{\circ} \mathrm{C}$. The evolution of $\omega_{\text {ath }}$ to $\omega_{\text {iso }}$ was $^{761}$ much slower in the as-extruded material than the cold- ${ }^{762}$ rolled material. Dark-field TEM imaging suggested that ${ }^{763}$ the $\alpha$ may nucleate from isothermal $\omega$ in this material, as previously suggested by Nag et al. $[15,16]$.

In TEM, it was found that $\omega$ particles were localised in regions of certain grains for all conditions in the ${ }^{-765}$ extruded material, whereas they were well distributed throtigh all grains in the cold-rolled material.

XRD shows clear peaks from the $\omega$ phase in both sam ${ }^{-769}$ ples following the longest time thermal exposures. $\quad{ }_{771}^{770}$

The room temperature SANS measurements of both $h_{72}$ samples showed no strong scattering from fine particles. ${ }^{773}$
This reinforces the argument that athermal $\omega$ has the same composition as the $\beta$ phase, as a neutron scattering contrast due to different element distributions in each phase is required for neutron scattering.

During thermal exposure at $400^{\circ} \mathrm{C}$ the precipitation of the scattering phase was far more rapid in the cold-rolled sample than the as-extruded. From SANS modelling and based upon TEM it is suggested that the scattering phase was isothermal $\omega$ for the extruded material, with discshaped particles. It is not possible to conclusively state the scattering is arising from the $\omega$ phase alone in the coldrolled data due to co-precipitation of the $\alpha$ phase, however based upon TEM diffraction patterns the authors believe scattering is predominantly from $\omega$. The $\phi(\Delta \rho)^{2}$ term increased very rapidly in the first $4 \mathrm{~h}$ of thermal exposure and then plateaued for the cold-rolled material, while the precipitation process was more linear in the as-extruded sample over the first $12 \mathrm{~h}$. The rapid evolution of the SANS $\phi(\Delta \rho)^{2}$ term of the cold-rolled sample, when compared to the as-extruded sample, is most likely due to a greater initial presence of athermal $\omega$ and/or a higher dislocation density.

The scattering intensity is very sensitive to the distribution of $\mathrm{Ti}$ and $\mathrm{Nb}$ in the alloy. With modelling it is shown that the $\omega_{\text {iso }}$ volume fraction in the cold-rolled + heat-treated material was far greater than the equivalent as-extruded material, and that it was also far more depleted in Nb. This is supported by the higher intensities in the $\omega$ TEM diffraction spots in the cold-rolled material. Sensible limits are suggested for the range of volume fraction and $\mathrm{Nb}$ partitioning for both processing conditions.

The rapid isothermal $\omega$ precipitation occurring in the cold-rolled sample corresponded to a significant improvement in hardness, from $280 \mathrm{Hv}$ to $400 \mathrm{Hv}$ in $6 \mathrm{~h}$.

\section{Acknowledgements}

JC, VV, NGJ and DD would like to acknowledge funding from EPSRC under grant EP/H0004882/01. JC and MO would also like to acknowledge fellowship funding provided by JSPS. This work utilizes the Oak Ridge National Laboratory's High Flux Isotope Reactor, which is sponsored by the Scientific User Facilities Division, Office of Basic Energy Sciences, U.S. Department of Energy. We would like to thank Matthias Knop at Imperial, Mark Ward at the University of Birmingham and Richard Dashwood at Warwick University for their help with sample manufacture and preparation.

\section{References}

[1] Saito T et al. Science 2003;300:464

[2] Boyer RR, Briggs RD. J Mater Eng Perform 2005 14:681

[3] Raghunathan SL, Stapleton AM, Dashwood RJ, Jackson M, Dye D. Acta Mater 2007 55:6861

[4] Nag S, Banerjee R, Fraser HL. J Mater Sci 2005 16:679

[5] Banerjee S, Tewari R, Dew GK. Int J Mater Sci 2006 97:963

[6] Ramsteiner et al. Acta Mater 2008 56(6):1298

[7] Duerig TW, Williams JC. In: Boyer RR, Rosenberg HW, eds., AIME, New York, USA, 1984:19-67 
[8] Nag S et al. Phy Rev Lett 2011 106:245701

[9] Jones NG, Dashwood RJ, Jackson M, Dye D. Acta Mater 2009 $57: 3830$

10] Furuta $\mathrm{T}$ et al. In: Lutjering G, ALbrecht J, eds., Ti-2003 Science and Technology, WILEY-VCH, Weinheim, Germany, 2004:1519-1526

[11] Collins DM, Heenan RK, Stone HJ. Metal Mater Trans A 2011 42:49

[12] Miller RJR, Messoloras S, Stewart RJ, Kostorz G. J Appl Cryst 1978 11:583

[13] Veron M, Bastile P Acta Mater 1997 45:3277

[14] Strunz P, Mukherji D, Gilles R, Wiedenmann A, Roesler J Fuess H J Appl Cryst 34:541

[15] Nag S, Banerjee R, Fraser HL. J Mater Sci 2009;44:808

[16] Nag S, Banerjee R, Srinivasan R, Hwang JY, Harper M, Fraser HL. Acta Mater 2009 57:2136

[17] Jones NG, Talling RJ, Lindley TC, Dye D. In: L Zhou et al. eds., Ti2011 Science and Technology: Proceedings of the 12th World Conference on Titanium. Science Press, Beijing, China. 2012:1169-1173

[18] Talling RJ, Dashwood RJ, Jackson M, Dye D. Acta Mater 2009 $57: 1188$

[19] Obbard EG, Hao YL, Akahori T, Talling RJ, Niinomi M, Dye D, Yang R. Acta Mater 201058:3557

[20] Coakley J, Reed RC, Warwick JLW, Rahman KM, Dye D. Acta Mater 2012;60:2729

[21] Stone HJ, Holden TM, Reed RC. Acta Metall 1999;47:4435

[22] Ma S, Rangaswamy P, Majumdar BS. Scr Mater 2003;48:525

[23] Ma S, Brown D, Bourke MAM, Daymond MR, Majumdar BS. Mater Sci Eng A 2005;399:141

[24] Daymond MR, Preuss M, Clausen B. Acta Mater 2007;55:3089

[25] Preuss M, da Fonesca JQ, Grant B, Knoche E, Moat R, Daymond M. In: Reed RC, Green KA, Caron P, Gabb TP Fahrmann MG, Huron ES, Woodard SA, eds., Superalloys 2008. TMS, PA, 405-414

[26] Dye D, Coakley J, Vorontsov VA, Stone HJ, Rogge RB. Scr Mater 2009;48:525

[27] Coakley J, Dye D. Scri Mater 2012;67:435

[28] Wignall GD, Littrell KC, Hetter WT, Melnichenko YB, Kailey KM, Lynn GW, Myles DA, Urban VS, Buchanan MV, Selby DL, Bulter PD J Appl Cryst 2012;45:990

[29] Hull AW Phys Rev 1921;18:88

[30] Wyckoff RWG In: Crystal structures. 2nd Edition, Vol. 3, Interscience Publishers, New York, New York, 1963:7-83

[31] Jamieson JC Science 1963;140:72

[32] Warwick J.L.W, Coakley J, Raghunathan S.L, Talling R.J, Dye D. Acta Mater 2012;60:4117

[33] Kline SRJ. J Appl Cryst 2006;39(6):895

[34] Heenan RK. RAL Report 1989;89

[35] Alina G, Butler P, Cho J, Doucet M, Kienzle P. "SAS analysis software", to be published.

[36] King SM. In: Pethrick RA, Dawkins JV, eds., Modern techniques for polymer characterisation. Wiley, Chichester, 1999:171-232

[37] van de Hulst HC. Light Scattering by Small Particles. Wiley, 1957

[38] Livsey I. J Chem Soc., Faraday Trans. 2 1987;83(8):1445

[39] Ashcroft NW, Lekner J. Phys Rev 1966;145:83

[40] Porod G. Kolloiz-Z 1951;124:83

[41] Sears VF. Neutron News 1992;(3)3:26

[42] Ohnuma M, Suzuki J, Ohtsuka S, Kim S.-W, Kaito T, Inoue M, Kitazawa H. Acta Mater 2009;(3)57:5571

[43] Ikeda M, Ueda M, matsunaga R, Ogawa M, Niinomi M. Mater Trans 2009;(50)12:2737 
Figure 3

a)

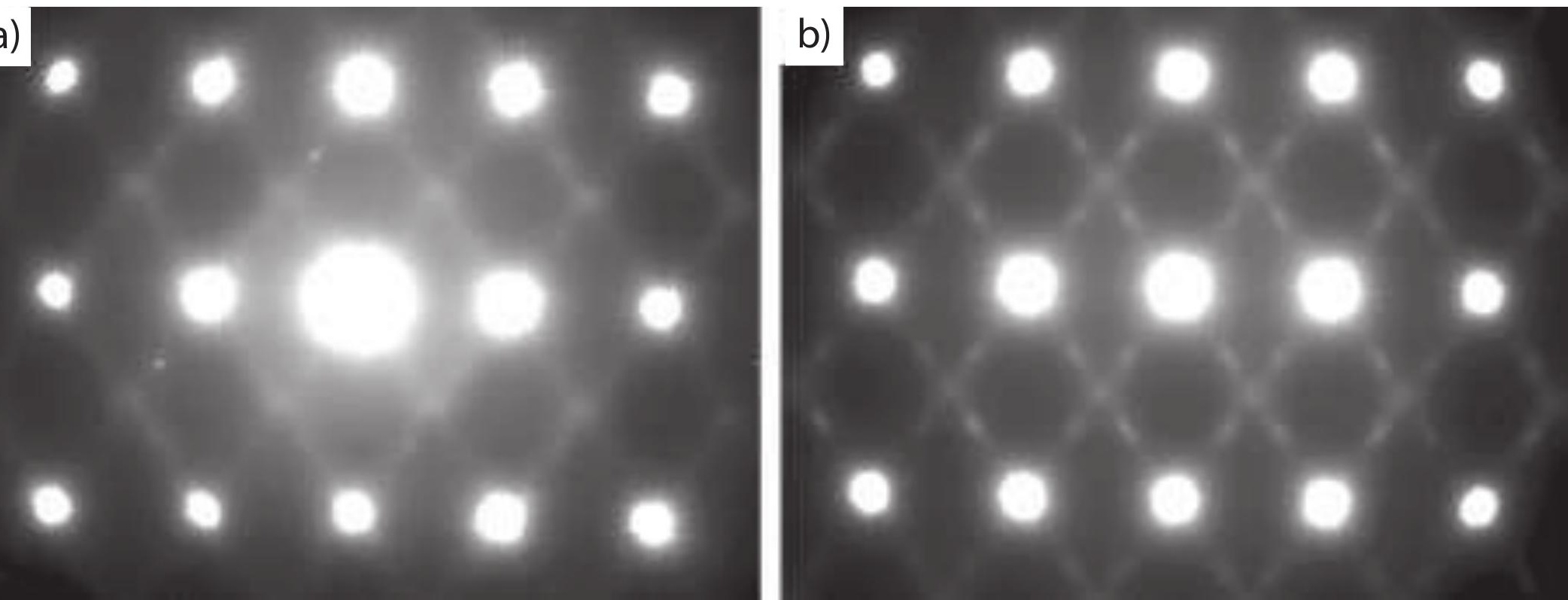


As Extruded (AE)

$90 \%$ Cold Rolled (CR)

$0.25 \mathrm{hrs}$

$2.5 \mathrm{hrs}$

$12.5 \mathrm{hrs}$
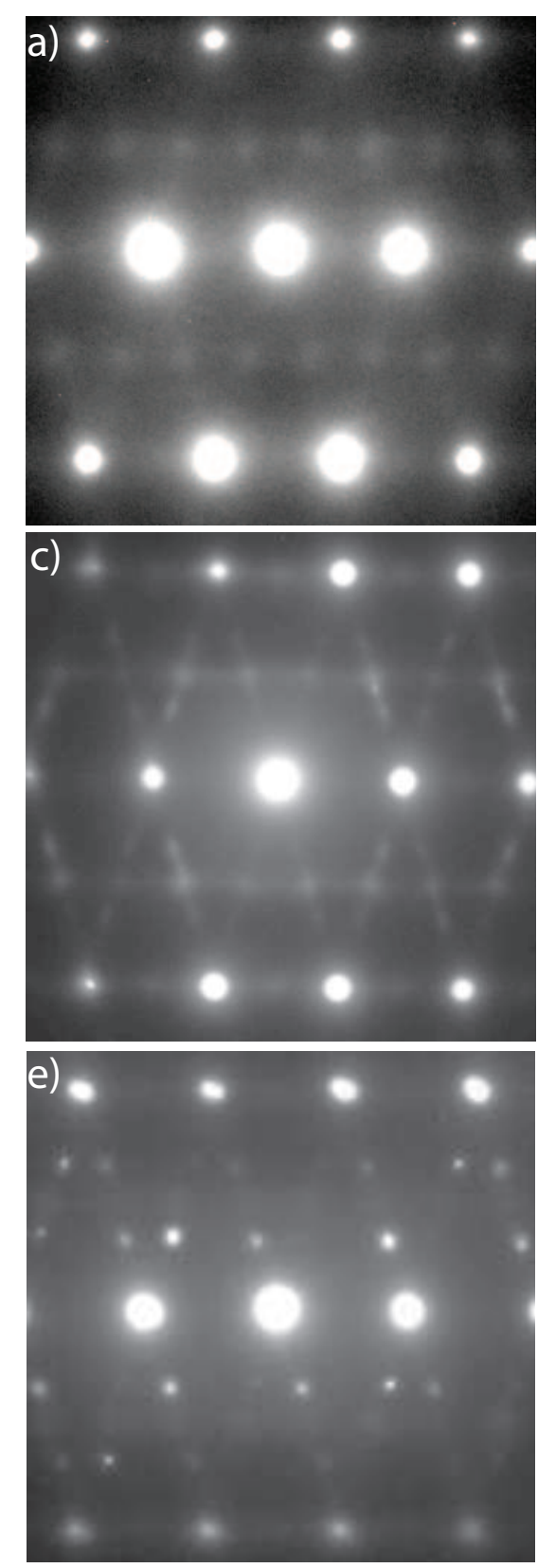

g)

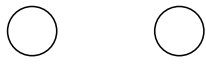

$\mathrm{O} O$

$\omega 1(10 \overline{1} \overline{1})$

00

O $\bigcirc 0^{\omega 2(1 \overline{1} 0 \overline{1})}$

$16 \mathrm{hrs}$

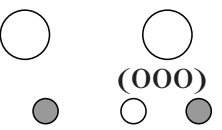

$\omega 1(\overline{1} 100) \omega 2(\overline{1} 010)$

0000

0
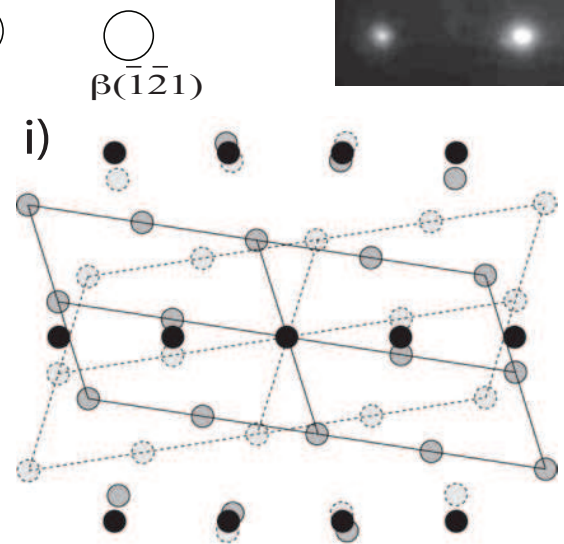

Figure 4
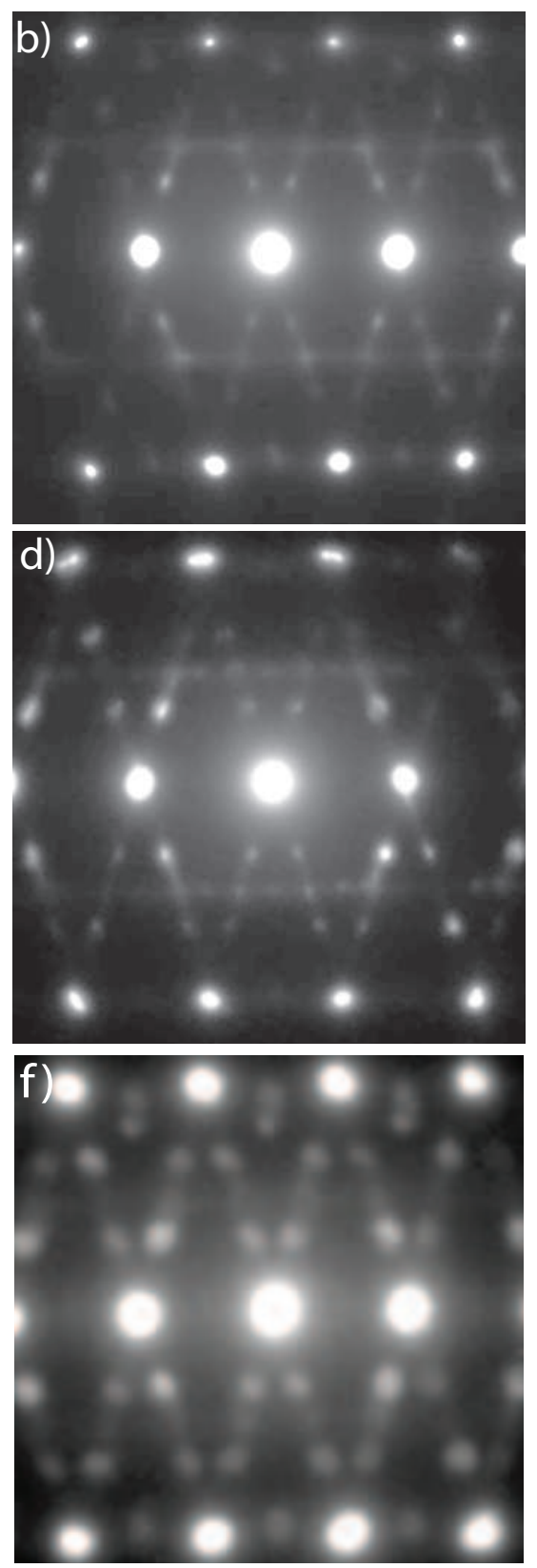

h)

$\bullet$
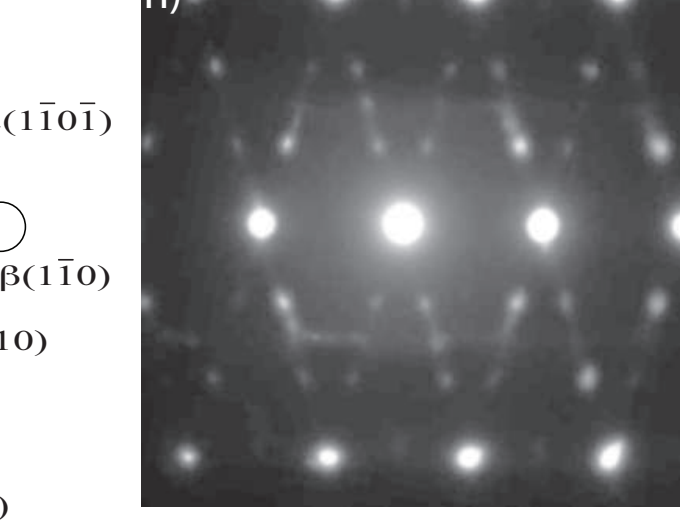
Figure 6

$\mathrm{Q}\left(\stackrel{\circ}{ }^{-1}\right)$
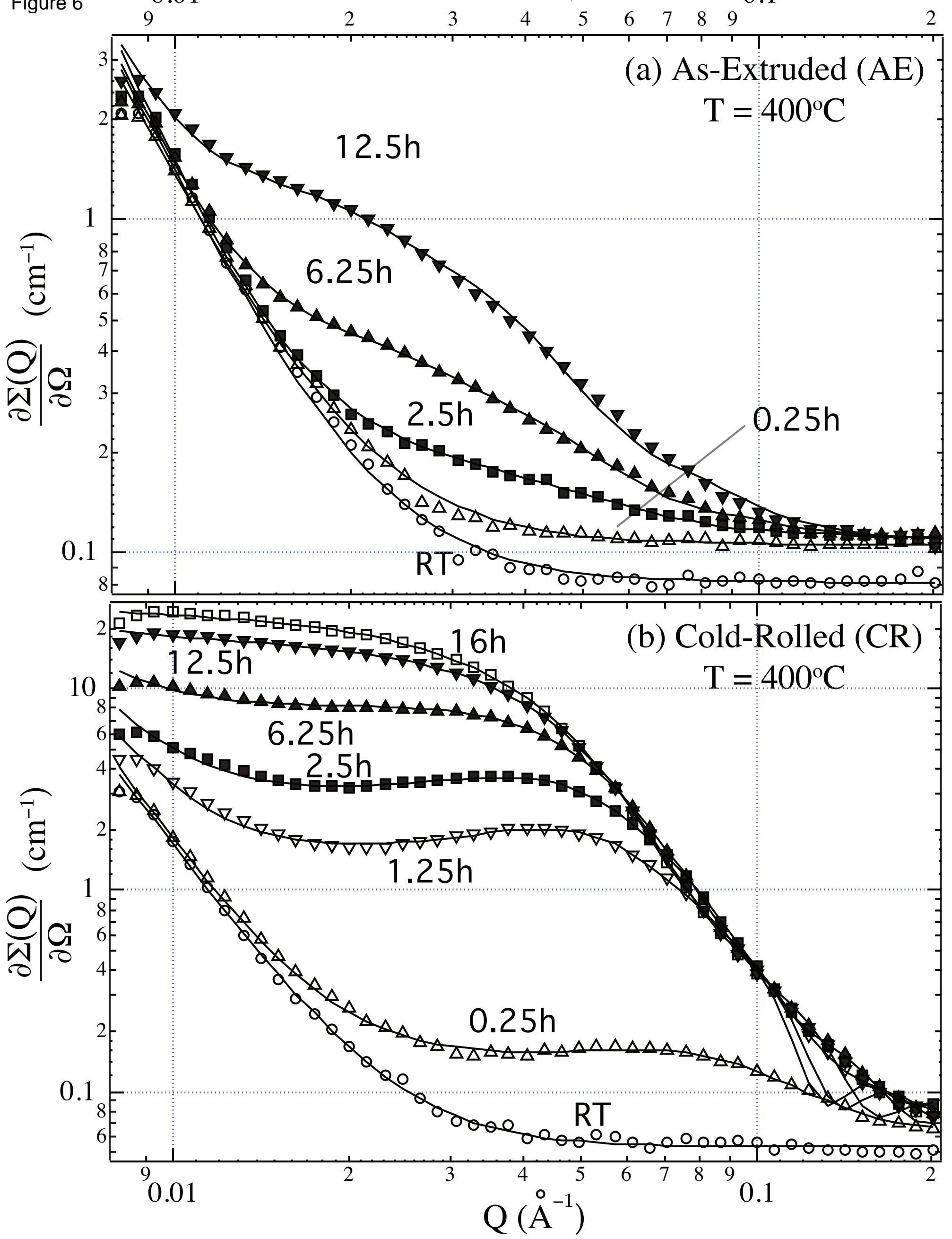
Figure 10

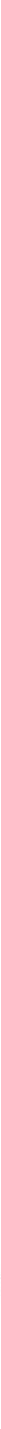


Figure 11

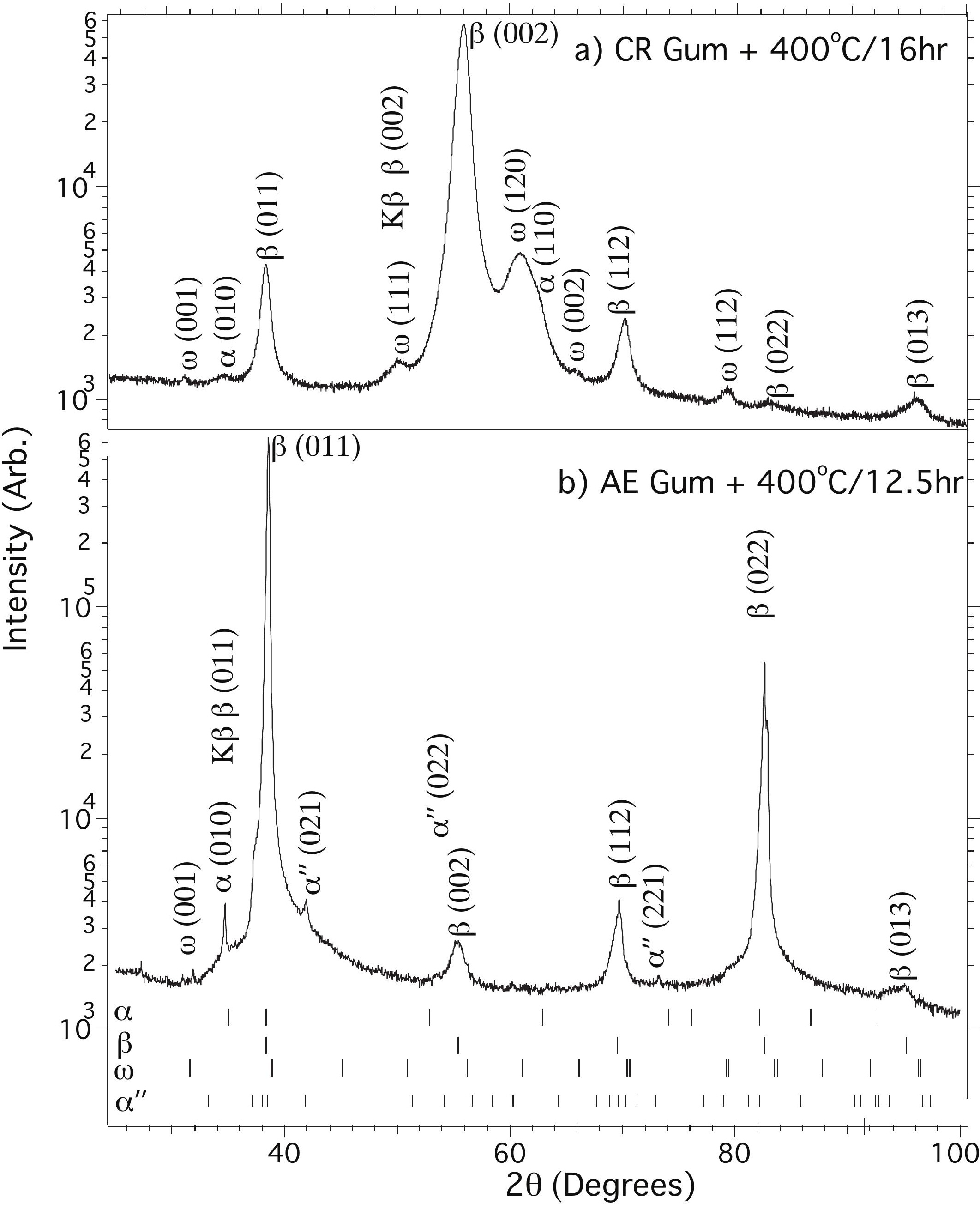

